\title{
Selenium Species: Current Status and Potentials in Cancer Prevention and Therapy
}

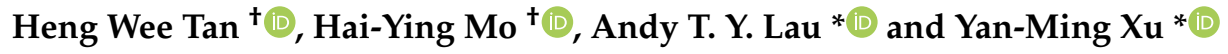 \\ Laboratory of Cancer Biology and Epigenetics, Department of Cell Biology and Genetics, Shantou University \\ Medical College, Shantou 515041, China; hwtan@stu.edu.cn (H.W.T.); 16hymo@stu.edu.cn (H.-Y.M.) \\ * Correspondence: andytylau@stu.edu.cn (A.T.Y.L.); amyymxu@stu.edu.cn (Y.-M.X.); \\ Tel.: +86-754-8853-0052 (A.T.Y.L.); +86-754-8890-0437 (Y.-M.X.) \\ + These authors contributed equally to this work.
}

Received: 15 November 2018; Accepted: 20 December 2018; Published: 25 December 2018

\begin{abstract}
Selenium (Se) acts as an essential trace element in the human body due to its unique biological functions, particularly in the oxidation-reduction system. Although several clinical trials indicated no significant benefit of Se in preventing cancer, researchers reported that some Se species exhibit superior anticancer properties. Therefore, a reassessment of the status of Se and Se compounds is necessary in order to provide clearer insights into the potentiality of Se in cancer prevention and therapy. In this review, we organize relevant forms of Se species based on the three main categories of Se-inorganic, organic, and Se-containing nanoparticles (SeNPs) - and overview their potential functions and applications in oncology. Here, we specifically focus on the SeNPs as they have tremendous potential in oncology and other fields. In general, to make better use of Se compounds in cancer prevention and therapy, extensive further study is still required to understand the underlying mechanisms of the Se compounds.
\end{abstract}

Keywords: selenium species; Se-containing nanoparticles; anticancer; chemotherapeutics; epigenetics

\section{Introduction}

Selenium (Se) is an essential micronutrient for the human body that is mainly obtained through diet and/or nutritional supplement [1]. Trace amounts of Se are required for maintaining optimal health as Se is a component of the selenoproteins (mostly in the form of amino acid selenocysteine) that participate in a wide range of cellular physiological processes. These processes include, but are not limited to, thyroid hormone regulation [2], redox homeostasis [3-5], inflammatory and immunological responses [6-8], carbohydrate metabolism [9], cardiovascular [10] and reproductive [11,12] health, and brain function maintenance [13-15]. Se deficiency is associated with numerous human diseases with various degrees of illnesses $[16,17]$. For instance, the Keshan disease (fatal cardiomyopathy due to viral infection) [18] and Kashin-Beck disease (chronic osteochondropathy) [19] are a few typical examples of Se deficiency-related diseases, which often occur endemically in the population living in regions with Se-poor soil. Excessive Se can be toxic and may lead to selenosis $[17,20]$. Currently, the recommended dietary allowance of Se for adults is set at $55 \mu \mathrm{g}(0.7 \mu \mathrm{mol}) /$ day [21]. Individuals with daily Se intake less than $\sim 15 \mu \mathrm{g}$ appear to be at risk of Se deficiency-related diseases, whereas those who consume over $400 \mu \mathrm{g} /$ day are prone to Se toxicity, although some studies have shown that safe levels of Se intake may be much lower than anticipated [16,21].

The relationship between Se and cancer, particularly in gastrointestinal and prostate cancer, was discovered in the middle of the 19th century, which then raised interest in the contribution of Se supplements to cancer prevention and therapy [22-24]. During half a century of exploration, many novel forms of Se compounds have been discovered and tested, and some have shown 
promising anticancer activity $[25,26]$. A double-blind, placebo-controlled, and randomized clinical trial carried out in the 1990s, the Nutritional Prevention of Cancer (NPC) trial, has provided us the early evidence supporting Se as a potential chemopreventive agent [27-29]. However, to date, none of the Se compounds have been clinically recognized as anticancer drugs, partly because, over the years, researchers have obtained conflicting results within and between epidemiological, clinical, and laboratory studies [30,31]. Notably, in contrast with the NPC trial, subsequent clinical trials such as the Selenium and Vitamin E Cancer Prevention Trial (SELECT) failed to demonstrate the anticancer effects of Se [32-34]. Some of these conflicting results showed that Se compounds not only failed to exert their cancer prevention or anticancer ability as anticipated but, in some cases, may even promote cancer [35]. Recent epidemiologic evidence suggests that chronic exposure to inorganic Se may increase cancer risk [36]. As a result, the dual role of Se compounds in carcinogenesis, especially in relation to the aspects of oxidative stress and angiogenesis, has been proposed and recently summarized [31]. So far, there is no clear conclusion on the circumstances under which a particular Se compound prevents or enhances carcinogenesis, perhaps due to the wide variety of Se speciations and their diverse effects at different concentrations on different metabolic pathways of cells and tissues [37,38]. Se or Se-containing compounds can be grouped into three main categories: inorganic, organic (also known as the organoselenium compounds), and Se-containing nanoparticles (SeNPs). In order to better utilize the anticancer properties of Se species, it is necessary to thoroughly evaluate the current status of Se species. Here, we systematically organize the relevant forms of Se species, with slightly more emphasize on SeNPs, and review their recent developments and potential in cancer prevention and therapy.

\section{Anti- or Pro-Cancer?}

Several Se compounds derived from all the three groups of Se (inorganic compounds, organoselenium compounds, and SeNPs) have shown possible anticancer ability. It is generally accepted that Se compounds exert their anticancer ability mainly through their direct or indirect antioxidant properties that intracellularly maintain the redox status and protect healthy cells from reactive oxygen species (ROS)-induced oxidative damage [39]. ROS are free radicals with unpaired electrons generated during normal biophysiological function. The evidence is strong that excessive ROS promotes carcinogenesis via elevated oxidative stress and increased DNA mutation [40]. Cancer cells are often characterized by their ability to produce and cope with an increased amount of ROS [41]. In other words, increased dependence on an antioxidant defense system is one of the principal characteristics of cancer cells. Despite the links between ROS and cancer formation, however, optimal (usually low) levels of ROS are actually beneficial as they play important roles in regulating many biological functions. Some enzymes and cells (e.g., white blood cells) can deliberately produce a range of superoxide radicals to kill invading pathogens $[39,42]$. ROS can also destroy damaged cells by promoting cellular senescence and apoptosis and thus eliminate the formation of cancer [41,42]. Such a dual role of ROS may explain why conflicting results for Se species, as "antioxidants", are often observed in cancer research. To further complicate the situation, other research found that some selenoproteins could actually behave as prooxidants instead of antioxidants, demonstrating both cancer-inhibiting and -promoting features in a cell type-, genotype-, and dosage-dependent manner [43-47]. For example, thioredoxin reductase 1, an essential redox regulating selenoprotein, can change from an anti- to a pro-oxidant and can both inhibit or promote carcinogenesis $[44,46]$.

In addition to oxidative stress regulation, the duality of Se compounds on angiogenesis has been discovered $[31,38]$. Angiogenesis refers to the physiological process responsible for the formation and growth of micro-blood vessels from pre-existing vasculature, which is one of the most important mechanisms for cells to obtain oxygen and nutrients. The roles of angiogenesis in relation to cancer development and metastasis have been studied extensively, and therapy explicitly targeting angiogenesis has become a promising approach for cancer treatment [48]. In vitro and in vivo studies showed that some Se compounds, such as the monomethylated Se amino acid methylselenocysteine (MSC), could inhibit cancer growth through its antiangiogenic properties [49-51]. MSC might also 
normalize the blood vessels and thus enhance delivery of a range of chemotherapeutic drugs and simultaneously reduce their toxicity [52-56]. Conversely, opposite results in which pro-angiogenic responses of Se-selenoproteins/compounds in normal or cancer cells have also been reported [57,58]. Thus, the dual role and narrow window between the beneficial and toxic effects of Se compounds often limit their potential for clinical application.

The dual effect of Se mentioned in this section is often restricted to the inorganic and organic Se compounds, and so far, research on anticancer activity of SeNPs, the emerging special form of Se species, appears to be positive. The use of SeNPs has had a revolutionary impact on cancer therapy, and they have shown tremendous potential compared to "ordinary" inorganic and organic Se compounds [59-62]. However, knowledge regarding the cytotoxicity and other possible adverse effects of these SeNPs in humans is still lacking, and further extensive research is required [63,64]. So far, all Se compounds are considered non-carcinogenic with the exception of selenium sulfide, which is categorized as a probable human carcinogen. Overall, in order to determine the potential of Se compounds in cancer prevention and therapy, multiple factors (e.g., speciation, concentration, targeting cell type, and cell state/condition) must be considered. In the following sections, we organize relevant forms of Se species and discuss their potential roles in cancer treatment based on recently published data.

\section{Se-Containing Compounds and Their Usage in Oncology}

All three main categories of Se (inorganic, organic, and SeNPs) contain compounds with potential anticancer properties. For inorganic and organic Se compounds, research has found that they are both metabolized differently and have varied mechanisms of action in diverse bio-physiological processes, including their roles in cancer [65]. Both forms of Se compounds can be readily absorbed by the human body, but only organic Se compounds, usually in the forms of amino acids (e.g., selenomethionine (SeMet) and selenocysteine), can be better retained and used [65]. The cancer prevention ability of a range of inorganic and organic Se compounds has been supported by a large number of publications from a wide range of studies under different settings, including biochemical, epidemiological, clinical, and animal studies $[38,44,46,66-68]$. However, toxicity risks accompanied by the use of these Se compounds have also been recorded. Although organic forms of Se may have lesser toxic effects than inorganic Se compounds [69], in reality, the toxic effects of Se are determined by multiple factors, with the forms of Se and dosage exposure being two of the most important parameters [26]. Despite the greater toxic effects, inorganic Se compounds may have an advantage in certain aspects of cancer therapy as described below.

\subsection{Inorganic Se Compounds}

Se exists in four natural valence states: elemental Se $(0)$, selenide $\left(-2 ; \mathrm{Se}^{2-}\right)$, selenite $\left(+4 ; \mathrm{SeO}_{3}{ }^{2-}\right)$, and selenate $\left(+6 ; \mathrm{SeO}_{4}{ }^{2-}\right.$ ). In Figure 1, we display the chemical structures of some of the representative Se compounds. A more detailed list of classification of Se compounds based on their structural features is summarized by Sanmartín et al. [70]. The functional and toxic effects of inorganic Se compounds differ according to their valence states. In Choi et al. [71], various concentrations of sodium selenate $\left(\mathrm{Na}_{2} \mathrm{SeO}_{4}\right)(5,10,30$, and $50 \mu \mathrm{M}$ for $48 \mathrm{~h})$ and sodium selenite $\left(\mathrm{Na}_{2} \mathrm{SeO}_{3}\right)(0.1,0.25$, and $0.5 \mu \mathrm{M}$ for $48 \mathrm{~h}$ ) along with three other organic Se compounds (SeMet, MSC, and methylseleninic acid (MSA)) were tested for their ability to sensitize human oral squamous carcinoma (KB) cells resistant to chemotherapeutic drug vincristine (KBV20C). They found that although all five Se compounds appeared to be able to sensitize KBV20C to the same extent as the sensitive parent $\mathrm{KB}$ cells, only selenate produced a higher sensitizing effect on the KBV20C cells by arresting the cell cycle at G2-phase and activating apoptotic pathways. However, opposite results were obtained by Takahashi et al. [72], where they showed that human oral squamous carcinoma (HSC-3) cells were more sensitive to $\mathrm{Na}_{2} \mathrm{SeO}_{3}$ and selenium dioxide $\left(\mathrm{SeO}_{2}\right)$, but not sodium selenate at concentrations ranging from 1 to $1000 \mu \mathrm{M}(72 \mathrm{~h})$. Pronounced anti-proliferative effect of selenite (5-100 $\mu \mathrm{M}$ for $2-5$ days) against three 
oral cancer cell lines (HSC-3, HSC-4, and SAS) was reported [73]. This study also suggested that selenite had a better anticancer effect than the two other organoselenium compounds (SeMet and MSC) tested.

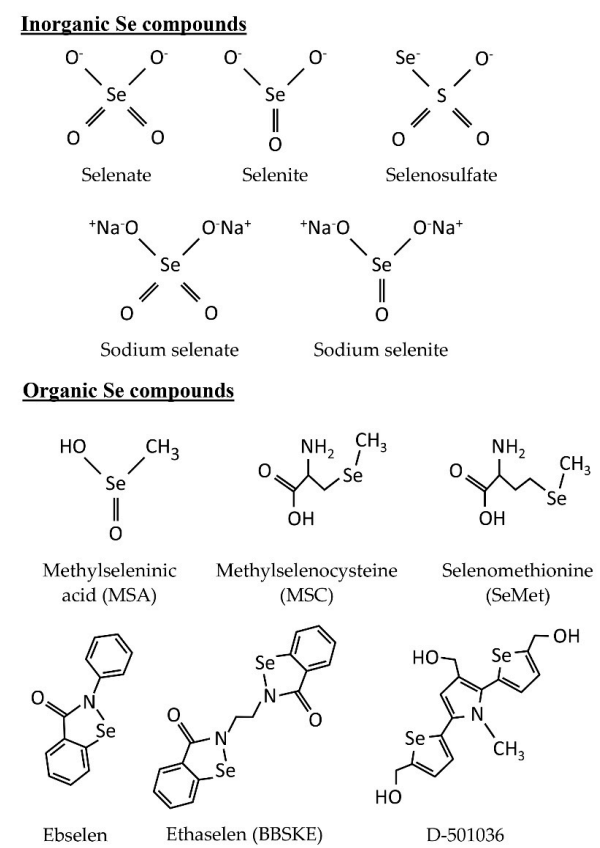

Figure 1. Chemical structures of selected representative inorganic and organic Se compounds discussed in this review.

Selenite is the most studied form of inorganic Se compounds as it exhibits excellent chemopreventive and anticancer features [74]. Selenite could effectively inhibit cell proliferation of various types of cancer cells, including lung cancer, which is the most common and deadliest cancer worldwide [75]. Among different human cancer cell lines tested, lung cancer cells, in general, appeared to be especially sensitive to selenite [76-79]. Olm et al. [80] indicated that selenite cytotoxicity ( $5 \mu \mathrm{M}$ for $5 \mathrm{~h}$ ) was correlated with Se uptake of three lung cancer cell lines (H157, H611, and U2020) and that high concentrations $(>1 \mathrm{mM})$ of selenate were non-toxic for these cell lines. Selenite was suggested to play a role in natural killer (NK) cell-based anticancer immunotherapy where it could increase the susceptibility of cancer cells to CD94/NK group 2A-positive NK cells, and has possible clinical applications in lung cancer patients [81]. The synergistic effect of selenite and thioredoxin reductase inhibitors (e.g., ethaselen and auranofin) was detected in human ovarian and lung cancer cell lines $[82,83]$. These results demonstrated the potential of Se compounds to enhance the activity and reduce the toxicity of anticancer drugs including those commonly used in chemotherapy (e.g., cisplatin, docetaxel, 5-FU, oxaliplatin, and irinotecan) [84-86]. Se compounds appear to be more effective in inhibiting the growth of anticancer drug-resistant cancer cells compared with drug-sensitive cancer cells via deactivating various resistance mechanisms used by the cancer cells. Chemotherapeutic drug-resistant lung cancer cells were revealed to be generally more sensitive to selenite (ranging from 0.1 to $100 \mu \mathrm{M}$ for $48 \mathrm{~h}$ and up to 4 days) compared to drug-sensitive cancer cells $[82,87,88]$. In addition to the above-mentioned in vitro studies, a phase I clinical trial published demonstrated the beneficial effects of selenite in cancer patients, especially in lung cancer patients who were resistant to cytostatic drugs [76].

Notably, the above results, however, do not necessarily mean that selenite is superior to other inorganic Se compounds in terms of cancer prevention and therapy. For instance, selenate might be more effective than selenite under certain circumstances as described earlier, even in the same type of cancer albeit different cell lines [71,72]. Inorganic Se such as selenosulfate $\left(\mathrm{SeSO}_{3}{ }^{-}\right)$was reported to have generally greater cytotoxic effects on cancer cells but was less toxic in healthy cells than selenite, depending on the cell types and the presence or absence of supplement amino acids that may affect the 
uptake of selenite [89]. Both $\mathrm{SeSO}_{3}{ }^{-}$and selenite might have the potential to work as a remedy against chemotherapy toxicity $[76,84]$. It was shown that hydrogen selenide $\left(\mathrm{H}_{2} \mathrm{Se}\right)$, a common intermediate of dietary Se metabolism produced by reduced selenite, could trigger the apoptosis of cancer cells (HepG2, HeLa, and MCF-7 cells) via accumulation in mitochondria induced by selenite, which would subsequently damage mitochondrial function and structure and lead to cell death [90].

\subsection{Organic Se Compounds}

Organic Se compounds attract considerable attention in the field of cancer research mainly due to their lower toxicity risk and ability to deliver significant anticancer activity, comparable or sometimes even better than inorganic Se compounds [69]. Organic Se compounds can be classified into different families based on their functional chemical structures: Selenides/diselenides, selenocyanates, selenoaminoacid derivatives (e.g., SeMet and MSC), methylseleninic acid (MSA; $\mathrm{CH}_{3} \mathrm{SeO}_{2} \mathrm{H}$ ), Se-heterocyclic compounds, and other miscellaneous Se-containing compounds (Figure 1). These organoselenium compounds exhibit anticancer and chemopreventive activity through diverse mechanisms of action, including reduction of oxidative stress [91], induction of apoptotic events [92-94], and enhancement of chemotherapeutic drug activity [95-97]. To date, many scientific studies on organoselenium compounds is available, many of which investigated their roles in cancer prevention and therapy. Several excellent reviews have listed a range of organoselenium compounds based on different classifications and summarized their functions in oncology [31,38,70,98]. Additionally, the potential anticancer and chemopreventive activity of selenides/diselenides [99] and selenocyanates [100] have been extensively reviewed.

Organoselenium compounds have the potential to be used as anti-neoplastic agents against solid tumors. Since necrosis of cancer cells is linked to host inflammatory response and may lead to treatment complications, the anti-necrotic and pro-apoptotic feature of some organic Se compounds is therefore largely preferred in cancer therapy [101]. Selenoaminoacid derivatives, such as SeMet and MSC, at low concentrations (as low as $0.113 \mu \mathrm{M}$ ), were shown to be able to promote apoptosis in solid tumors of various types of human cancer, whereas the control non-tumorigenic mammary epithelial cells (MCF-10A) required substantially high concentrations (up to $87.9 \mu \mathrm{M}$ for $72 \mathrm{~h}$ ) of organic Se to display sensitivity to apoptosis [92]. Owing to the ability of organoselenium compounds to induce apoptosis, their synergistic effects on chemotherapeutic drugs against cancer were observed [53,95-97]. MSC may also provide additional protection from the toxicity of anticancer drugs [54,56].

MSA is an oxidized form of methylselenol $\left(\mathrm{CH}_{3} \mathrm{Se}^{-}\right)$converted from selenoaminoacids (e.g., SeMet and MSC) [43]. In vivo and in vitro studies have indicated that MSA is an excellent anticancer agent comparable to SeMet or selenite against a range of cancer models, including lung [102], breast [103,104], melanoma [105], and prostate cancer in particular [106-108]. In a recent study, MSA showed significant cytotoxic effects toward monocytic leukemia cells (THP1) compared with the healthy peripheral blood mononuclear (PBM) cells [109]. MSA also enhanced the anticancer activity of radiation and chemotherapeutic drugs (cytosine arabinoside and doxorubicin) in the malignant THP1 cells in a dose-dependent manner $(2.5,5$, and $15 \mu \mathrm{M}$ for $48 \mathrm{~h})$ [109]. At lower concentrations, MSA protected normal PBM cells from radiation and chemotherapeutic drugs, whereas at higher concentrations, MSA was considered toxic and could increase the cytotoxicity of radiation but not chemotherapy [109]. In another study, MSA was able to inhibit the proliferation, migration, and adhesion of HeLa cells more effectively than SeMet and MSC, and it showed synergistic anticancer activity with S-adenosyl-methionine-a universal methyl group co-substrate involved in multiple intermediary metabolites [110]. MSA was shown to be able to reverse the tamoxifen resistance of breast cancer cells when used in combination with tamoxifen through the activation of caspase- 9 and then caspase-8, resulting in the induction of the intrinsic, mitochondrial apoptotic pathway [111]. A novel programmed cell death mechanism (entosis) induced by MSA and methylselenoesters was identified in pancreatic cancer Panc-1 cells [112]. Entosis is characterized by the invasion of a living cell to another cell's cytoplasm resulting in endophagocytosis and the formation of cell-in-cell structures. 
Other groups of selenocompounds, such as the selenocynates and Se-containing heterocycles, also contained several Se compounds with promising chemopreventive or anticancer properties, ranging from the well-studied $p$-xylene selenocyanate and benzyl selenocyanate to the recently reported novel active compounds that combine the selenocyanate moiety with different heterocycles, quinones, or steroids [100]. Heterocyclic organoselenium compounds, such as ebselen and ethaselen (also known as BBSKE) are small molecules that have potential in cancer therapy $[113,114]$. A list of these heterocyclic compounds and their anticancer ability is summarized in Fernandes and Gandin [38] and Sanmartíin et al. [70]. The selenophene-based triheterocyclic derivative 2,5-bis(5-hydroxymethyl-2-selenienyl)-3-hydroxymethyl- $N$-methylpyrrole (D-501036) has received increasing attention due to its broad-spectrum anticancer activity against several human cancer cells in a dose- and time-dependent manner [115-117]. D-501036 selectively induces apoptosis and double-strand DNA breaks in cancer cells, and is especially effective against chemotherapeutic drug-resistant cancer cells with overexpression of P-glycoprotein/multidrug-resistant protein [116]. Further study has suggested that enhanced non-homologous end-joining DNA repair activity was involved in the development of D-501036-resistance in cancer cells [117]. Previously in a cisplatin-resistant prostate cancer model, the degree of drug-resistance was found to be associated with the oxidative system in the cells [118]. Thus, it was likely that cancer cells, and in particularly drug-resistant cancer cells, have higher Se uptake compared with benign cells due to the redox state of Se and the oxidative system of the cancer cells $[118,119]$.

Previous clinical trials (e.g., NPC) have shown that dietary Se supplements (Se-enriched yeast) could reduce the risk of multiple cancers [27-29]. However, subsequent trials (e.g., SELECT and Southwest Oncology Group (SWOG) S9917), tested using SeMet, showed no such beneficial effects [32,33]. In a clinical trial, it was indicated that SeMet did not improve quality of life or survival outcomes of patients with head and neck squamous cell cancer undergoing concurrent chemoradiation [35]. These conflicting results may be partially explained by the selection of the Se compound administered: $200 \mu \mathrm{g} /$ day of Se-enriched yeast in the NPC trial and $200 \mu \mathrm{g} /$ day of SeMet in SELECT and SWOG S9917. Although SeMet is the major component of Se-enriched yeast, it is possible that other components in Se-enriched yeast (e.g., MSC) may be contributing to the overall chemopreventive effect of Se observed in the NPC trial. This speculation, however, cannot be verified since there were substantial batch-to-batch variations in specific organoselenium compounds in the samples of NPC yeast [32]. Additionally, no significant benefit in the prevention of second primary tumors was detected in a phase III clinical trial (ECOG 5597) that administrated $200 \mu \mathrm{g} /$ day of Se-enriched yeast to patients with completely resected stage I non-small-cell lung cancer [34]. Despite these negative findings, most of these trials suggested that Se supplement was safe to consume. Thus, organic Se may be useful in cancer therapy but appears to confer no significant benefit in the prevention of cancer.

\subsection{SeNPS}

Since the late 1990s, application of nanotechnology in the bio-medical field has received extensive attention. Owing to their biocompatibility, biodegradability, and designability, nanomaterials are increasingly utilized in cancer therapy and diagnosis as pharmaceutical products, drug carriers, imaging agents, and diagnostic reagents to overcome some limitations of the traditional materials [120]. SeNPs, as emerging Se species, are considered to be promising medical materials, according to their reported chemotherapeutical properties [121,122], nutritional effects [123], and relatively low toxicity compared with some other Se compounds [3,124]. The chemotherapeutical potency of SeNPs and their proposed anticancer mechanisms have been reviewed by Menon et al. [125]. Here, we systematically tabulated a list of SeNPs based on data published in 2017 and the first half of 2018 and arranged them according to their reported functions: chemotherapy (Table 1), drug delivery (Table 2), diagnosis (Table 3), and SeNPs with multiple functions (Table 4). The potential of these SeNPs in cancer prevention and treatment, along with their synthesis methods, are discussed below. 
Table 1. Summary of recent work on Se-containing nanoparticles (SeNPs) with potential in cancer chemotherapy.

\begin{tabular}{|c|c|c|c|c|c|c|c|}
\hline SeNP & Material & $\begin{array}{l}\text { Shape and Size } \\
(\mathrm{nm})\end{array}$ & Effects & Dosage & Pathway & Model & Reference \\
\hline $\begin{array}{l}\text { Acinetobacter sp. } \\
\text { SW30 SeNPs }\end{array}$ & $\begin{array}{l}\text { Acinetobacter sp. } \\
\text { SW30 }\end{array}$ & $\begin{array}{c}\text { Amorphous } \\
\text { nanospheres, } 78 \mathrm{~nm} ; \\
\text { Polygonal-shaped, } \\
79 \mathrm{~nm}\end{array}$ & $\begin{array}{l}\text { Selectively against breast cancer } \\
\text { cells and non-toxic to normal cells }\end{array}$ & - & - & $\begin{array}{l}\text { Breast cancer cells (4T1, } \\
\text { MCF-7) and noncancer } \\
\text { cells (NIH/3T3, HEK293) }\end{array}$ & [126] \\
\hline $\begin{array}{c}\text { Bacillus } \\
\text { licheniformis JS2 } \\
\text { derived biogenic } \\
\text { SeNPs }\end{array}$ & $\begin{array}{c}\text { Bacillus } \\
\text { licheniformis JS2, } \\
\text { aerobic condition } \\
\text { in } 1.8 \mathrm{mM} \\
\mathrm{Na}_{2} \mathrm{SeO}_{3} \text { stress }\end{array}$ & Spherical, $110 \mathrm{~nm}$ & $\begin{array}{l}\text { Stimulated ROS production and } \\
\text { caused damage to the } \\
\text { mitochondria without affecting } \\
\text { the cell membrane integrity. } \\
\text { Induced overexpression of } \\
\text { necroptotic genes and promoted } \\
\text { RIP3-independent necroptosis }\end{array}$ & $\begin{array}{l}\text { Concentration of } \\
2 \mu \mathrm{g} \mathrm{Se} / \mathrm{mL}\end{array}$ & - & $\begin{array}{l}\text { Human prostate } \\
\text { adenocarcinoma cell } \\
\text { line (PC-3) }\end{array}$ & [127] \\
\hline $\begin{array}{l}\text { Blg stabilized } \\
\text { SeNPs }\end{array}$ & $\begin{array}{l}\text { Ascorbic acid, Blg, } \\
\mathrm{Na}_{2} \mathrm{SeO}_{3}\end{array}$ & $\begin{array}{l}\text { Spherical, mean } \\
\text { particle size of } \\
36.8 \pm 4.1 \mathrm{~nm}\end{array}$ & $\begin{array}{l}\text { Lower cytotoxicity than } \mathrm{Na}_{2} \mathrm{SeO}_{3} \text {. } \\
\text { Similar cell growth inhibition on } \\
\text { both colon cancer cell and } \\
\text { corresponding normal cell }\end{array}$ & - & - & $\begin{array}{l}\text { Human colon } \\
\text { adenocarcinoma cells } \\
\text { (HCT116) and colon } \\
\text { normal cell (CCD112) }\end{array}$ & [124] \\
\hline $\begin{array}{c}\text { Ferulic } \\
\text { acid-modified } \\
\text { SeNPs }\end{array}$ & $\begin{array}{l}\mathrm{Na}_{2} \mathrm{SeO}_{3} \text {, ascorbic } \\
\text { acid, ferulic acid } \\
\text { solution }\end{array}$ & $\begin{array}{c}\text { Amorphous, } \\
\text { average diameter of } \\
109 \mathrm{~nm}\end{array}$ & $\begin{array}{l}\text { Induced intracellular ROS } \\
\text { generation and MMP disruption }\end{array}$ & $>100 \mu \mathrm{g} / \mathrm{mL}$ & $\begin{array}{c}\text { Caspase- } 3 / 9 \\
\text { mitochondrial } \\
\text { pathway }\end{array}$ & HepG2 & [128] \\
\hline $\begin{array}{l}\text { Folic acid } \\
\text { surface-coated Se } \\
\text { nanoparticles } \\
\text { (FA@-SeNPs) }\end{array}$ & $\begin{array}{l}\text { Folic acid, } \mathrm{SeO}_{2} \\
\text { solution, ascorbic } \\
\text { acid solution }\end{array}$ & $\begin{array}{c}\text { Rod-shaped } \\
(400 \times 100 \mathrm{~nm})\end{array}$ & $\begin{array}{l}\text { Showed antiproliferative effect } \\
\text { against } 4 \mathrm{~T} 1 \text { cells. Significantly } \\
\text { increased the lifespan and } \\
\text { reduced the tumor size of } \\
\text { cancerous animals. Had better } \\
\text { absorption toward cancer cells. } \\
\text { Exhibited a better in vivo } \\
\text { anticancer effect compared } \\
\text { to SeNPs }\end{array}$ & $\begin{array}{c}200 \mu \mathrm{g} / \mathrm{mL} \\
\text { in vitro and } \\
300 \mathrm{mg} / \text { week } \\
\text { in vivo }\end{array}$ & - & $\begin{array}{l}\text { 4T1 breast cancer cell line } \\
\text { and inbred Balb/c mice }\end{array}$ & [129] \\
\hline $\begin{array}{c}\text { Folic } \\
\text { acid-conjugated } \\
\text { SeNPs } \\
\text { (FA@SeNPs) }\end{array}$ & $\begin{array}{c}\text { Folic acid, CTS, } \\
\mathrm{Na}_{2} \mathrm{SeO}_{3 \prime} \\
\text { ascorbic acid }\end{array}$ & Spherical, 192 nm & $\begin{array}{l}\text { Able to synergistically enhance } \\
\text { the anticancer efficacy and colony } \\
\text { formation inhibition ability of } \\
\text { radioactive }{ }^{125} \text { I seeds. Increased } \\
\text { ROS overproduction. Induced } \\
\text { DNA damage and activated the } \\
\text { mitogen-activated protein kinase } \\
\text { and TP53 signaling pathways }\end{array}$ & $\begin{array}{l}5 \mathrm{mg} / \mathrm{kg} \text { of } \\
\text { FA@SeNPs with } \\
\text { an intratumor } \\
\text { injection strategy } \\
\text { every other day } \\
\text { and / or implanted } \\
\text { with radioactive } \\
\text { 125I seeds }\end{array}$ & $\begin{array}{c}\text { DNA } \\
\text { damage-mediated } \\
\text { p53 and MAPK } \\
\text { signaling } \\
\text { pathways }\end{array}$ & $\begin{array}{l}\text { Michigan Cancer } \\
\text { Foundation-7 cell (MCF-7) } \\
\text { and female nude mice }\end{array}$ & [130] \\
\hline
\end{tabular}


Table 1. Cont.

\begin{tabular}{|c|c|c|c|c|c|c|c|}
\hline SeNP & Material & $\begin{array}{l}\text { Shape and Size } \\
(\mathrm{nm})\end{array}$ & Effects & Dosage & Pathway & Model & Reference \\
\hline $\begin{array}{l}\text { PEC-decorated Se } \\
\text { nanoparticles }\end{array}$ & $\begin{array}{c}\text { Selenite and } \\
\text { ascorbic acid, PEC }\end{array}$ & $\begin{array}{l}\text { Spherical, average } \\
\text { size of } \sim 41 \mathrm{~nm}\end{array}$ & $\begin{array}{l}\text { PEC as a surface decorator could } \\
\text { be effectively used to improve the } \\
\text { stability and antioxidant capacity } \\
\text { of SeNPs }\end{array}$ & - & - & $\begin{array}{c}\text { Cancer cells (SPCA-1 and } \\
\text { HeLa) and normal cells } \\
\text { (RWPE-1) }\end{array}$ & [131] \\
\hline $\begin{array}{c}\text { Pleurotus } \\
\text { tuber-regium } \\
\text { (PTR)-conjugated } \\
\text { SeNPs } \\
\text { (PTR-SeNPs) } \\
\end{array}$ & $\begin{array}{l}\text { Sclerotia of tiger } \\
\text { milk mushrooms, } \\
\mathrm{Na}_{2} \mathrm{SeO}_{3} \\
\text { ascorbic acid }\end{array}$ & $\begin{array}{l}\text { Se concentration: } \\
1.35 \pm 0.12 \mu \mathrm{M} ; \\
\text { particle size: } \\
80.0 \pm 12.3 \mathrm{~nm}\end{array}$ & $\begin{array}{l}\text { Triggered intracellular G2/M } \\
\text { phase arrest and apoptosis. } \\
\text { Activated autophagy to promote } \\
\text { the death of cancer cells }\end{array}$ & - & $\begin{array}{l}\text { Beclin 1-related } \\
\text { signaling } \\
\text { pathways }\end{array}$ & $\begin{array}{l}\text { Human colon cancer cells } \\
\text { (HCT 116) }\end{array}$ & [132] \\
\hline SeNPs & $\begin{array}{l}\text { Se powder, } \\
\mathrm{Na}_{2} \mathrm{SO}_{4} \\
\text { acetic acid }\end{array}$ & Spherical, $12-30 \mathrm{~nm}$ & $\begin{array}{l}\text { Induced TAMs isolated from } \\
\text { DL-bearing mice. Induced ROS } \\
\text { generation, macrophage } \\
\text { polykaryon formation, and } \\
\text { adhesion molecules (CD54 or } \\
\text { ICAM-1), and fusion receptors } \\
\text { (CD47 and CD172 } \alpha \text { ) expression } \\
\text { on TAMs. Decreased tumor } \\
\text { cell proliferation }\end{array}$ & $\begin{array}{l}20-50 \mathrm{ng} \text { for } \\
10^{6} \text { cells }\end{array}$ & - & $\begin{array}{l}\text { Daltons lymphoma cells } \\
\text { and DL-bearing BALB/c } \\
(\mathrm{H} 2 \mathrm{~d}) \text { strain of mice }\end{array}$ & [133] \\
\hline SeNPs & $\mathrm{SeO}_{2}$ & - & $\begin{array}{l}\text { Combination of AET and SeNP } \\
\text { supplementation effects } \\
\text { anti-tumor immune responses } \\
\text { in splenocytes }\end{array}$ & $\begin{array}{l}6 \text { weeks of AET } \\
\text { and SeNP } \\
\text { administration } \\
\text { (100 mg three } \\
\text { times / week). Oral } \\
\text { administration in } \\
\text { doses of } 100 \text { and } \\
200 \mathrm{~mL} \text { per mouse }\end{array}$ & - & $\begin{array}{l}\text { Mice bearing the } 4 \mathrm{~T} 1 \\
\text { mammary carcinoma }\end{array}$ & [122] \\
\hline SeNPs & $\begin{array}{l}\mathrm{Na}_{2} \mathrm{SeO}_{3} \\
\mathrm{GSH}, \mathrm{BSA}\end{array}$ & $\begin{array}{l}20-70 \mathrm{~nm} \text {, average } \\
\text { size of } 40 \mathrm{~nm}\end{array}$ & $\begin{array}{l}\text { Able to rapidly, massively, and } \\
\text { selectively accumulate in cancer } \\
\text { cells. Showed stronger } \\
\text { pro-oxidant property } \\
\text { than selenite }\end{array}$ & - & - & $\begin{array}{l}\text { Male Kunming mice and } \\
\text { Murine H22 } \\
\text { hepatocarcinoma cells }\end{array}$ & [134] \\
\hline
\end{tabular}

Abbreviations, AET: aerobic exercise training; Blg: beta-lactoglobulin; BSA: bovine serum albumin; CTS: chitosan; DL: dalton's lymphoma; MMP: mitochondrial membrane potential;

PEC: pectin; ROS: reactive oxygen species; SeNPs: Se-containing nanoparticles; TAMs: tumor-associated macrophages; TrxR: thioredoxin reductase. 
Table 2. Summary of recent work on SeNPs with potential for anti-cancer drug delivery.

\begin{tabular}{|c|c|c|c|c|c|c|c|}
\hline SeNP & Material & $\begin{array}{l}\text { Shape and Size } \\
(\mathrm{nm})\end{array}$ & Effects & Dosage & Pathway & Model & Reference \\
\hline $\begin{array}{c}\text { CPT and } \\
\text { DOX-loaded } \\
\text { PEG-b-PBSe core } \\
\text { crosslinked micelles } \\
\text { (CPT/DOX-CCM) }\end{array}$ & $\begin{array}{c}\text { Diselenide diols } \\
\text { precursors, } \\
\text { PEG45-based RAFT } \\
\text { agent, CPT, DOX }\end{array}$ & Spherical, $129 \mathrm{~nm}$ & $\begin{array}{l}\text { Features include high drug } \\
\text { loading, visible light-induced in } \\
\text { situ crosslinking, improved } \\
\text { physiological stability, } \\
\text { optimized pharmacokinetics, } \\
\text { and tumor-specific combined } \\
\text { drug release }\end{array}$ & $\begin{array}{c}1 \mathrm{mg} \text { CPT or DOX } \\
\text { equivalent per } \mathrm{kg} \\
\text { every four days in } \\
24 \text { days }\end{array}$ & - & $\begin{array}{l}\text { Human breast cancer cell } \\
\text { line (MCF-7) and mouse } \\
\text { mammary tumor cell } \\
\text { line (EMT-6) }\end{array}$ & [135] \\
\hline $\begin{array}{l}\text { CTS-modified Se } \\
\text { nanoparticle }\end{array}$ & $\begin{array}{l}\mathrm{Na}_{2} \mathrm{SeO}_{3} \text {, ascorbic } \\
\text { acid solution } \\
\text { (vitamin C), CTS }\end{array}$ & $400-4000 \mathrm{~cm}^{-1}$ & $\begin{array}{l}\text { Slow-release carrier conjugated } \\
\text { to the TNF- } \alpha \text {-derived peptide } \\
\text { P16, G0/G1 cell-cycle arrest, } \\
\text { and apoptosis }\end{array}$ & - & $\begin{array}{l}\text { p38MAPK/JNK } \\
\text { pathway }\end{array}$ & $\begin{array}{c}\text { Prostate cancer cells } \\
\text { (DU145) and normal } \\
\text { human prostate epithelial } \\
\text { cells (RWPE-1) }\end{array}$ & [136] \\
\hline $\begin{array}{l}\text { DOX-SeNPs@TMC-FA } \\
\text { (pH-sensitive) }\end{array}$ & $\begin{array}{l}\text { Selenite, ascorbic } \\
\text { acid, folic acid-N } \\
\text { trimethyl CTS } \\
\text { (TMC-FA) }\end{array}$ & $\begin{array}{c}\text { An average } \\
\text { diameter of } 50 \mathrm{~nm}\end{array}$ & $\begin{array}{l}\text { Enhanced the activity of DOX } \\
\text { by approximately } 10 \text {-fold for a } \\
\text { reduced } \mathrm{IC}_{50} \text { value compared } \\
\text { to free DOX }\end{array}$ & - & $\begin{array}{c}\text { Apoptosis } \\
\text { pathway involved } \\
\text { caspase- } 3 \text { and } \\
\text { PARP proteins }\end{array}$ & $\begin{array}{c}\text { Ovarian cancer DOX } \\
\text { sensitive (OVCAR8) } \\
\text { and resistant } \\
\text { (NCI/ADR-RES) cells }\end{array}$ & [137] \\
\hline $\begin{array}{l}\text { EPI-loaded-NAS-24- } \\
\text { functionalized } \\
\text { PEIPEG-5TR1 } \\
\text { aptamer coated } \\
\text { SeNPs (ENPPASe } \\
\text { complex) }\end{array}$ & $\begin{array}{l}\mathrm{Na}_{2} \mathrm{SeO}_{3}, \\
\text { EPI-loaded-NAS-24- } \\
\text { functionalized } \\
\text { PPA complex }\end{array}$ & $68.2 \pm 6 \mathrm{~nm}$ & $\begin{array}{l}\text { Able to provide high loading of } \\
\text { EPI and NAS-24. Reduced the } \\
\text { toxicity in non-target cells. } \\
\text { Reduced the cell viability in the } \\
\text { target cancer cells. Reduced the } \\
\text { tumor growth in cancer-bearing } \\
\text { mice compared to EPI } \\
\text { treatment alone }\end{array}$ & - & - & $\begin{array}{l}\text { Human breast carcinoma } \\
\text { cell (MCF7), murine colon } \\
\text { carcinoma cell (C26) and } \\
\text { human hepatocellular } \\
\text { carcinoma cell (HepG2) }\end{array}$ & [138] \\
\hline FA-CP/SeNPs & $\begin{array}{l}\mathrm{Na}_{2} \mathrm{SeO}_{3} \text {, folic acid } \\
\text { decorated cationic } \\
\text { pullulan (FA-CP) }\end{array}$ & $\begin{array}{c}\text { Flower-like } \\
\text { structure, } \\
\text { approximately } \\
50 \mathrm{~nm}\end{array}$ & $\begin{array}{l}\text { Higher loading capacity of } \\
\text { DOX. Less toxicity against } \\
\text { normal cells }\end{array}$ & - & - & $\begin{array}{l}\text { KB cancer cells line and } \\
\text { normal cell line (L292) }\end{array}$ & [139] \\
\hline $\begin{array}{l}\text { Hyaluronic acid } \\
\text { Se-PEI nanoparticle }\end{array}$ & $\begin{array}{l}\mathrm{Na}_{2} \mathrm{SeO}_{3} \text {, ascorbic } \\
\text { acid, hyaluronic } \\
\text { acid, PEI }\end{array}$ & $70-180 \mathrm{~nm}$ & $\begin{array}{l}\text { Showed higher transfection } \\
\text { efficiency, greater gene } \\
\text { silencing ability, and stronger } \\
\text { cytotoxicity }\end{array}$ & - & - & $\begin{array}{l}\text { HepG2 cell, Lo2 cell and } \\
\text { xenograft mouse model }\end{array}$ & [140] \\
\hline $\begin{array}{c}\text { Nano-Se }+ \\
\text { Nano-fluorouracil }\end{array}$ & $\mathrm{Na}_{2} \mathrm{SeO}_{3}, \mathrm{GSH}, \mathrm{BSA}$ & $\begin{array}{c}\text { Spherical, ranged } \\
\text { from } 66.43 \mathrm{~nm} \text { to } \\
\quad 98.9 \mathrm{~nm}\end{array}$ & $\begin{array}{c}\text { Induced chemo-sensitivity of } \\
\text { 5-fluorouracil-encapsulated } \\
\text { poly (D, L-lactide-co-glycolide) } \\
\text { nanoparticles (nano-FU) in } \\
\text { cancer cells }\end{array}$ & $\begin{array}{l}0,2,4,6,8,10,30 \\
\quad \text { and } 50 \mu \mathrm{M}\end{array}$ & $\begin{array}{l}\text { Glucose uptake } \\
\text { slight blockage, } \\
\text { interaction } \\
\text { with } \mathrm{Zn}\end{array}$ & $\begin{array}{c}\text { Human breast cancer } \\
\text { (MCF7) and human } \\
\text { colorectal cancer Cell } \\
\text { (Caco-2) }\end{array}$ & [141] \\
\hline
\end{tabular}


Table 2. Cont.

\begin{tabular}{|c|c|c|c|c|c|c|c|}
\hline SeNP & Material & $\begin{array}{l}\text { Shape and Size } \\
(\mathrm{nm})\end{array}$ & Effects & Dosage & Pathway & Model & Reference \\
\hline Oil-soluble CdSe QD & $\begin{array}{l}\text { CdO, mineral oil, } \\
\text { oleic acid, Se }\end{array}$ & $\begin{array}{c}\text { DG-PEG-OC-9R, } \\
\text { near spherical, } \\
112.0 \pm 1.63 \mathrm{~nm} ; \\
\text { FA-PEG-OC-9R, } \\
\text { near spherical, } \\
115.2 \pm 1.94 \mathrm{~nm}\end{array}$ & $\begin{array}{l}\text { Could be used to evaluate the } \\
\text { hypoxic tumor cell-targeting } \\
\text { properties of the wrapped } \\
\text { CTS-based micelles }\end{array}$ & - & - & $\begin{array}{l}\text { Normoxic/hypoxic } \\
\text { HepG2 and HeLa cells }\end{array}$ & [142] \\
\hline $\begin{array}{l}\text { Oridonin-loaded } \\
\text { and GE11 peptide } \\
\text { conjugated SeNPs } \\
\text { (GE11-Ori-SeNPs) }\end{array}$ & $\begin{array}{l}\mathrm{Na}_{2} \mathrm{SeO}_{3} \text {, oridonin, } \\
\text { ascorbic acid, GE11 } \\
\text { polypeptide }\end{array}$ & $\begin{array}{l}\text { Near-spherical, } \\
\text { average diameter } \\
\text { of } 70 \mathrm{~nm}\end{array}$ & $\begin{array}{l}\text { The GE11 surface modification } \\
\text { provides targeting towards } \\
\text { cancer cells: oridonin releasing } \\
\text { induced cancer cell apoptosis. } \\
\text { Inhibited tumor growth via } \\
\text { inhibition of tumor } \\
\text { angiogenesis by reducing the } \\
\text { angiogenesis-marker CD31 and } \\
\text { activation of the immune } \\
\text { system by enhancing IL-2 and } \\
\text { TNF-a production }\end{array}$ & $\begin{array}{c}2.5,5, \text { and } 7.5 \\
\mathrm{mg} / \mathrm{kg} / \text { day for } 15 \\
\text { days through tail } \\
\text { intravenous } \\
\text { injection }\end{array}$ & $\begin{array}{c}\text { EGFR-mediated } \\
\text { PI3K/AKT and } \\
\text { Ras/Raf/MEK/ERK } \\
\text { pathway, } \\
\text { mitochondria- } \\
\text { dependent } \\
\text { pathway }\end{array}$ & $\begin{array}{l}\text { Human esophageal cancer } \\
\text { cell lines (KYSE-150 and } \\
\text { EC9706) and KYSE-150 } \\
\text { xenograft mice model }\end{array}$ & [143] \\
\hline $\begin{array}{c}\text { Se@MIL-101-(P + V) } \\
\text { siRNA }\end{array}$ & $\begin{array}{c}\text { MIL-101(Fe), } \\
\text { cysteine, } \mathrm{Na}_{2} \mathrm{SeO}_{3} \\
\text { siRNA }\end{array}$ & $\begin{array}{l}\text { Spherical, particle } \\
\text { size } 160 \mathrm{~nm} \text {, pore } \\
\text { diameter } 2.19 \mathrm{~nm}\end{array}$ & $\begin{array}{l}\text { Enhanced protection of siRNAs } \\
\text { against nuclease degradation. } \\
\text { Increased siRNA cellular } \\
\text { uptake and promoted siRNA } \\
\text { escape from } \\
\text { endosomes/lysosome to silence } \\
\text { MDR genes in MCF-7/T } \\
\text { (Taxol-resistance) cells. } \\
\text { Enhanced cancer therapeutic } \\
\text { efficacy and decreased systemic } \\
\text { toxicity in vivo }\end{array}$ & $\begin{array}{l}10 \mathrm{mg} / \mathrm{kg} \text { by } \\
\text { intravenous } \\
\text { injection for } 15 \mathrm{~d} \\
(12 \mu \mathrm{g} \text { of siRNA } \\
\text { per mouse })\end{array}$ & $\begin{array}{l}\text { p53, MAPK, and } \\
\text { PI3K/Akt }\end{array}$ & $\begin{array}{l}\text { MCF-7/T cells, paclitaxel } \\
\text { resistance MCF- } 7 / \mathrm{T} \text { cells } \\
\text { and nude mice }\end{array}$ & [144] \\
\hline
\end{tabular}

BSA: bovine serum albumin; CPT: camptothecin; CTS: chitosan; DOX: doxorubicin; EPI: epirubicin; GSH: glutathione; MDR: multidrug resistance; PPa: pyropheophorbide a; QD: quantum dots; RIS: risedronate sodium; SeNPs: Se-containing nanoparticles. 
Table 3. Summary of recent work on SeNPs with potential in cancer diagnosis.

\begin{tabular}{|c|c|c|c|c|c|c|}
\hline SeNP & Material & Shape and Size $(\mathrm{nm})$ & Effects & Dosage & Model & Reference \\
\hline $\begin{array}{c}\text { Anti-HE4 } \\
\text { IgG-HE4-anti- } \\
\text { HE4 } 4^{\text {CdSe/ZnS }} \\
\text { immunocomplex }\end{array}$ & $\begin{array}{l}\text { Anti-HE4 IgG } \\
\text { antibodies, } \\
\text { CdSe/ZnS QD }\end{array}$ & - & $\begin{array}{l}\text { Electrochemical immunosensor for HE4 } \\
\text { protein detection using QD as } \\
\text { electrochemically active labels of specific } \\
\text { antibodies. Contributed significantly to } \\
\text { the analytical performance of tumor } \\
\text { marker detection and met the exacting } \\
\text { requirements for HE4 protein } \\
\text { clinical monitoring }\end{array}$ & - & HE4 in human serum & [145] \\
\hline $\begin{array}{l}\text { Aptamer-modified } \\
\text { SeNPs (Apt-SeNPs) }\end{array}$ & - & $\begin{array}{l}\text { Spherical structures, } \\
\qquad 88 \pm 30 \mathrm{~nm}\end{array}$ & $\begin{array}{l}\text { Good chemical stability, water solubility, } \\
\text { and biocompatibility. Strong green } \\
\text { scattering light with a characterized } \\
\text { scattering peak at } 570 \mathrm{~nm} \text {. Precisely and } \\
\text { specifically target and image nucleolin } \\
\text { overexpressed cancer cells after being } \\
\text { modified with aptamers }\end{array}$ & - & $\begin{array}{l}\text { Human epidermoid } \\
\text { cancer (Hep-2) cells }\end{array}$ & [146] \\
\hline $\begin{array}{c}\text { CdTe/ZnSe } \\
\text { core/shell QDs }\end{array}$ & $\begin{array}{l}\mathrm{CdTe}, \mathrm{Na}_{2} \mathrm{TeO}_{3} \\
\mathrm{Zn}\left(\mathrm{CH}_{3} \mathrm{CO}_{2}\right)_{2} \\
\quad \mathrm{Na}_{2} \mathrm{SeO}_{3}\end{array}$ & $\begin{array}{l}\text { QD }(10 \pm 2 \mathrm{~nm}) \\
\text { QD+T }(13 \pm 2 \mathrm{~nm}) \\
\text { QD+C }(18 \pm 2 \mathrm{~nm}) \\
\text { QD+A }(71 \pm 2 \mathrm{~nm}) \\
\text { QD+G }(95 \pm 2 \mathrm{~nm})\end{array}$ & $\begin{array}{l}\text { Able to detect DNAs (directly from cell } \\
\text { extracts), damages to the DNA, } \\
\text { and mutations }\end{array}$ & - & $\begin{array}{l}\text { Prostate cancer (PC3) } \\
\text { and normal human } \\
\text { cells (PNT1A) }\end{array}$ & [147] \\
\hline $\begin{array}{l}\text { IL13 conjugated QD } \\
\text { (IL13QD) }\end{array}$ & $\begin{array}{c}\text { CdSe-based QD, } \\
\text { 1-ethyl-3-(3- } \\
\text { dimethylaminopropyl) } \\
\text { carbodiimide (EDC), } \\
\text { interleukin-13 (IL13) }\end{array}$ & $\begin{array}{l}\text { Core-shell structure, } \\
\text { a size range of } \\
15-20 \mathrm{~nm}\end{array}$ & $\begin{array}{l}\text { IL13R } \alpha 2 \text { can be detected in } \\
\text { cerebrospinal fluid by IL13QD. A higher } \\
\text { force of binding interaction between the } \\
\text { IL13QD and IL13R } \alpha 2 \text { expressing glioma } \\
\text { cells and exosomes secreted by glioma } \\
\text { stem cells was observed }\end{array}$ & - & $\begin{array}{l}\text { U251 human glioma } \\
\text { cells and CD133 } \\
\text { positive glioma } \\
\text { initiating cells (T3691) }\end{array}$ & [148] \\
\hline $\begin{array}{l}\text { SeNP loaded } \\
\text { imprinted core-shell } \\
\text { microcomposites } \\
\text { (SIMs) }\end{array}$ & $\begin{array}{l}\text { CTS, zeolite, } \mathrm{TiO}_{2} \\
\mathrm{Na}_{2} \mathrm{SeO}_{4}, \mathrm{Na}_{2} \mathrm{SeO}_{3}\end{array}$ & $\begin{array}{l}\text { Spherical, average } \\
\text { size of } 80 \mathrm{~nm}\end{array}$ & $\begin{array}{l}\text { Could be used for dot-blot } \\
\text { immunoassays for rapid serodiagnosis } \\
\text { of human lung cancer. The detection } \\
\text { time of the colloidal Se dot test for the } \\
\text { progastrin-releasing peptide (as a tumor } \\
\text { marker for small cell lung cancers) was } \\
\text { only } 5 \text { min }\end{array}$ & $\begin{array}{l}\text { Linear with the } \\
\text { concentration of antigen } \\
\text { within the concentration } \\
\text { range of } 0-105 \mathrm{pg} / \mathrm{mL} \text {. } \\
\text { The lowest concentration } \\
\text { to distinguish significant } \\
\text { positive results was } \\
\text { observed to be } 75 \mathrm{pg} / \mathrm{mL}\end{array}$ & $\begin{array}{l}\text { Human progastrin } \\
\text { releasing-peptide }\end{array}$ & [149] \\
\hline
\end{tabular}

CTS: chitosan; HE4: human epididymis protein 4; QD: quantum dots; SeNPs: Se-containing nanoparticles. 
Table 4. Summary of recent work on multi-functional SeNPs with potential in cancer-related research.

\begin{tabular}{|c|c|c|c|c|c|c|c|c|}
\hline SeNPs & Material & $\begin{array}{c}\text { Shape and Size } \\
(\mathrm{nm})\end{array}$ & Function $^{1}$ & Effects & Dosage & Pathway & Model & Reference \\
\hline $\begin{array}{l}\mathrm{Ag}_{2} \mathrm{Se} \text {-cetuximab } \\
\text { nanoprobes }\end{array}$ & $\begin{array}{l}\text { Bis(trimethylsilyl) } \\
\text { selenide, silver } \\
\text { acetate, } \\
\text { cetuximab }\end{array}$ & $\begin{array}{c}\text { Spherical, } \\
\text { diameter of } \\
2.8 \pm 0.5 \mathrm{~nm}\end{array}$ & $C$ and $E$ & $\begin{array}{l}\text { Displayed faster and more enrichment at } \\
\text { the site of cancer. Inhibited the tumor } \\
\text { growth and improved the survival rate of } \\
\text { the cancer-bearing nude mice model. } \\
\text { Combined targeted imaging and therapy }\end{array}$ & - & - & $\begin{array}{l}\text { Human tongue squamous cell } \\
\text { carcinoma cells (CAL-27) and } \\
\text { human immortalized } \\
\text { noncancerous keratinocytes } \\
\text { cells (HaCaT) and Balb/c mice }\end{array}$ & [150] \\
\hline $\begin{array}{l}\text { DOX-loaded } \\
\text { selenopolymeric } \\
\text { nanocarriers } \\
\text { (Se@CMHA- } \\
\text { DOX NPs) }\end{array}$ & $\begin{array}{l}\mathrm{Na}_{2} \mathrm{SeO}_{3}, \\
\text { ascorbic acid, } \\
\text { poly (ethylene } \\
\text { glycol) (PEG), } \\
\text { cetyl-modified } \\
\text { hyaluronic } \\
\text { acid, DOX }\end{array}$ & $\begin{array}{c}\text { Spherical, } \\
244 \pm 6.8 \mathrm{~nm}\end{array}$ & $A$ and $C$ & $\begin{array}{l}\text { Inhibited TrxR activity and augmented the } \\
\text { anticancer efficacy of DOX. Induced G2/M } \\
\text { cell cycle arrest and TP53-mediated } \\
\text { caspase-independent apoptosis. Reduced } \\
\text { tumor activity in a three-dimensional tumor } \\
\text { sphere model }\end{array}$ & $\begin{array}{l}5 \mu \mathrm{g} / \mathrm{mL} \\
\text { for } 48 \mathrm{~h}\end{array}$ & $\begin{array}{l}\text { Apoptotic } \\
\text { pathway }\end{array}$ & $\begin{array}{l}\text { MCF7 breast adenocarcinoma } \\
\text { cells and MCF7 tumor } \\
\text { sphere model }\end{array}$ & [151] \\
\hline HSAMSe@DOX & $\begin{array}{l}\mathrm{Na}_{2} \mathrm{SeO}_{3} \\
\text { L-ascorbic acid, } \\
\text { Human serum } \\
\text { albumin, DOX }\end{array}$ & $\begin{array}{l}\text { Homogeneous } \\
\text { spherical, } \\
\sim 80 \mathrm{~nm}\end{array}$ & $A$ and $C$ & $\begin{array}{l}\text { Synergistically enhanced the antitumor } \\
\text { activity of DOX and decreased the side } \\
\text { effects associated with DOX. Increased } \\
\text { tumor-targeting effects and enhanced } \\
\text { cellular uptake through nanoparticle } \\
\text { interact with SPARC protein }\end{array}$ & $\begin{array}{c}10 \mathrm{mg} / \mathrm{mL} \\
100 \mu \mathrm{L} \text { into the } \\
\text { veins of the tails }\end{array}$ & - & $\begin{array}{l}\text { MCF-7, MCF-10A, } \\
\text { MDA-MB-231, SKBR3 and } \\
\text { female BALB/C nude mice }\end{array}$ & [152] \\
\hline $\begin{array}{l}\mathrm{MoSe}_{2}\left(\mathrm{Gd}^{3+}\right)-\mathrm{PEG} \\
\text { nanosheets }\end{array}$ & $\begin{array}{l}\mathrm{NaMoO}_{4} \cdot 2 \mathrm{H}_{2} \mathrm{O} \\
\mathrm{Se}, \mathrm{NaBH}_{4} \\
\text { gadolinium(III) } \\
\text { chloride } \\
\text { hexahydrate }\end{array}$ & $\begin{array}{l}\text { Lamellar, } \\
100-150 \mathrm{~nm}\end{array}$ & $\mathrm{~B}, \mathrm{~F}$ and $\mathrm{G}$ & $\begin{array}{l}\text { Able to provide a strong contrast for } T 1 \\
\text { weighted magnetic resonance imaging. } \\
\text { Could be used as contrast agent for } \\
\text { photoacoustic imaging (PAI). Increased the } \\
\text { temperature to help kill cancer cells under } \\
\text { laser irradiation. Enhanced permeation and } \\
\text { retention effect in the tumor using magnetic } \\
\text { resonance photoacoustic bimodal imaging } \\
\text { in vivo. Suppressed tumors in mice by } \\
\text { injection with laser irradiation }\end{array}$ & - & - & $\begin{array}{c}\text { Hep G2 human hepatoma } \\
\text { carcinoma cells, BALB/c } \\
\text { nude mice }\end{array}$ & [153] \\
\hline $\begin{array}{l}\text { Paclitaxel-loaded } \\
\text { SeNPs }\end{array}$ & $\begin{array}{l}\mathrm{SeO}_{2} \text {, paclitaxel, } \\
\text { ascorbic acid, } \\
\text { pluronic F-127 }\end{array}$ & $\begin{array}{l}\text { Hydrodynamic } \\
\text { diameter, } 87 \mathrm{~nm} \text {, } \\
\text { spherical }\end{array}$ & $A$ and $B$ & $\begin{array}{l}\text { Significant antiproliferative activity against } \\
\text { cancer cells. G2/M phase arrest in a } \\
\text { dose-dependent manner leading to } \\
\text { apoptosis. Disruption of mitochondrial } \\
\text { membrane potential orchestrated with the } \\
\text { induction of reactive oxygen species leading } \\
\text { to the activation of caspases }\end{array}$ & - & MMP, caspases & $\begin{array}{l}\text { Lung cells (L-132), cervical } \\
\text { cancer cells (HeLa), breast } \\
\text { cancer cells, (MCF7), non-small } \\
\text { lung carcinoma cells (A549) } \\
\text { and colorectal adenocarcinoma } \\
\text { cells (HT29) }\end{array}$ & [154] \\
\hline $\begin{array}{l}\text { PPa@CTX-Se-OA/ } \\
\text { DSPE-PEG2k }\end{array}$ & $\begin{array}{l}\text { Cabazitaxel, } \\
\text { PPa, oleic acid, } \\
\text { Se powder, } \\
\text { DSPE-PEG2k }\end{array}$ & $\begin{array}{c}\text { Spherical, } \\
\text { average } \\
\text { diameter of } \\
104.1 \pm 3.1 \mathrm{~nm}\end{array}$ & $\mathrm{C}$ and $\mathrm{D}$ & $\begin{array}{l}\text { Light irradiation disassembles the structure } \\
\text { of ROS-responsive prodrug nanosystems by } \\
\text { cleaving the ROS-responsive linkers to } \\
\text { accelerate the release of the parent drug }\end{array}$ & $\begin{array}{c}200 \mathrm{ng} / \mathrm{mL} \text { for } \\
4 \mathrm{~h} \text { or } 24 \mathrm{~h}\end{array}$ & - & $4 \mathrm{~T} 1$ murine breast cancer cells & [19] \\
\hline
\end{tabular}


Table 4. Cont

\begin{tabular}{|c|c|c|c|c|c|c|c|c|}
\hline SeNPs & Material & $\begin{array}{l}\text { Shape and Size } \\
(\mathrm{nm})\end{array}$ & Function $^{1}$ & Effects & Dosage & Pathway & Model & Reference \\
\hline $\begin{array}{l}\text { Se/iron oxide } \\
\text { nanoparticles } \\
\text { (Se:IONP) }\end{array}$ & $\begin{array}{c}\mathrm{Na}_{2} \mathrm{SeO}_{3} \text {, acetic acid, } \\
\text { CTS, hydrophobic } \\
\text { IONP }\end{array}$ & $\begin{array}{l}\text { Spherical in a } \\
\text { transmission } \\
\text { electron microscope, } \\
\text { irregular in a } \\
\text { scanning electron } \\
\text { microscope, } 5-9 \mathrm{~nm}\end{array}$ & $\mathrm{~A}$ and $\mathrm{H}$ & $\begin{array}{l}\text { An iron oxide core produced by thermal } \\
\text { decomposition, followed by a silane ligand } \\
\text { exchange, a CTS coating, and Se decoration. } \\
\text { Reduced cancer cell viability }\end{array}$ & - & - & MB-231 breast cancer cells & [155] \\
\hline $\begin{array}{l}\text { Se-containing } \\
\text { hydroxyapatite/ } \\
\text { alginate } \\
\text { (SeHA/ALG) } \\
\text { composite } \\
\text { granules }\end{array}$ & $\begin{array}{c}\left(\mathrm{NH}_{4}\right)_{2} \mathrm{HPO}_{4} \\
\mathrm{Na}_{2} \mathrm{SeO}_{3} \cdot 5 \mathrm{H}_{2} \mathrm{O} \\
\mathrm{Ca}\left(\mathrm{NO}_{3}\right)_{2} \cdot 4 \mathrm{H}_{2} \mathrm{O} \\
\text { hydroxyapatite, } \\
\text { alginate sodium, RIS }\end{array}$ & $\begin{array}{l}\text { Spherical, } \\
1.1-1.5 \mathrm{~mm}\end{array}$ & $A$ and $C$ & $\begin{array}{l}\text { Biphasic process of releasing sufficient Se } \\
\text { and RIS against osteosarcoma cells }\end{array}$ & - & - & $\begin{array}{l}\text { Human osteoblast-like cell line } \\
\text { (Saos-2) and normal human } \\
\text { fetal osteoblasts (hFOB 1.19) }\end{array}$ & [156] \\
\hline $\begin{array}{l}\text { SeNPs-DOX- } \\
\text { ICG-RP }\end{array}$ & $\begin{array}{l}\text { L-ascorbic acid, } \\
\mathrm{Na}_{2} \mathrm{SeO}_{3} \text {, dual-target } \\
\text { (RC-12 and PG-6 } \\
\text { peptides), loaded } \\
\text { with both DOX } \\
\text { and ICG }\end{array}$ & $\begin{array}{c}\text { Sphere-like } \\
\text { morphology with } \\
\text { an average size of } \\
110 \mathrm{~nm}\end{array}$ & $B$ and $C$ & $\begin{array}{l}\text { NIR-laser irradiation that raised the } \\
\text { temperature of the nanosystem and allowed } \\
\text { nanoparticles to decompose and release } \\
\text { drugs accurately in the tumor site. Reduced } \\
\text { the damage of chemotherapy drugs to } \\
\text { normal tissue }\end{array}$ & - & - & HepG2 and normal L02 cells & [157] \\
\hline $\begin{array}{l}\text { Ultra-small } \\
\text { Nano-Se }\end{array}$ & $\mathrm{Na}_{2} \mathrm{SeO}_{3}, \mathrm{GSH}, \mathrm{BSA}$ & $\begin{array}{c}\text { Monodisperse } \\
\text { spherical shape } \\
\text { with a diameter } \\
\text { about } 27.5 \pm 4.3 \mathrm{~nm}\end{array}$ & $\mathrm{~A}$ and $\mathrm{F}$ & $\begin{array}{l}\text { Reinforced the toxic effects of irradiation, } \\
\text { leading to a higher mortality rate than either } \\
\text { treatment used alone. Induced cell cycle } \\
\text { arrest at the G2/M phase and the activation } \\
\text { of autophagy. Increased both endogenous } \\
\text { and irradiation-induced ROS formation. } \\
\text { Improved cancer cell sensitivity to the toxic } \\
\text { effects of irradiation }\end{array}$ & $\begin{array}{c}0.15 \text { and } 0.3 \\
\mu \mathrm{g} / \mathrm{mL}, \mathrm{X} \text {-rays } \\
(6-\mathrm{MeV}, 200 \\
\text { cGy/min) }\end{array}$ & - & MCF-7 breast carcinoma cells & [158] \\
\hline
\end{tabular}

${ }^{1}$ Function, A: chemotherapy; B: photothermal therapy; C: drug delivery; D: photodynamic therapy; E: diagnosis; F: radiosensitizer; G: imaging; H: magnetically-targeted. Abbreviations, BSA: bovine serum albumin; CTS: chitosan; DOX: doxorubicin; GSH: glutathione; ICG: indocyanine green; MMP: mitochondrial membrane potential; PPa: pyropheophorbide a; RIS: risedronate sodium; ROS: reactive oxygen species; SeNPs: Se-containing nanoparticles; TrxR: thioredoxin reductase. 
Many methods have been reported for SeNPs preparation, which are generally classified into three broad categories based on different producing principles: chemosynthesis, biosynthesis, and physical synthesis [159]. Among them, chemosynthesis is considered the most common method to prepare SeNPs. In chemosynthesis, Se in the +4 -valence state, such as selenite, selenious acid, or $\mathrm{SeO}_{2}$, is frequently employed as precursors, whereas reducing agents (e.g., ascorbic acid and glutathione [GSH]) and stabilizing agents (e.g., chitosan and pectin) are used for SeNPs formation and maintenance $[131,141,159,160]$. SeNPs synthesized in the $\mathrm{Na}_{2} \mathrm{SeO}_{3}-\mathrm{GSH}$ redox system tended to gather in cancer cells and presented stronger pro-oxidant activity comparing to selenite [134]. However, to optimize their function in cancer therapy and prevention, chemosynthetic SeNPs are usually decorated with specific molecules, which endow them with ideal features to meet the demands of practical applications. For example, decorating SeNPs with other bioactive molecules can enhance the therapeutic effects upon certain types of cancers when compared with non-decorated SeNPs $[128,129,161]$. Aside from direct therapeutic effects, chemically modified SeNPs can function as vehicles that endow the carried objects with favorable properties like tumor targeting $[150,157]$, high efficacy [137,144], and low toxicity [139]. Notably, chemosynthetic SeNPs were also examined as diagnostic agents $[145,147,149]$, imaging agents $[146,153]$, and radiosensitizers $[130,158]$. Overall, chemosynthesis is the most common method used to obtain and modify SeNPs, because the process is easy to implement and control. Nevertheless, environmental pollution and accumulation of chemosynthetic materials in the body should also be considered.

In contrast to chemosynthetic SeNPs, biosynthetic SeNPs appear to be environmentally friendlier and biologically safer. Thus, there has been increased focus upon biosynthetic SeNPs, partly also due to their extraordinary biocompatibility, sustainability, and economy [162]. These organismal materials mediating SeNPs are extracellularly or intracellularly manufactured with selective plants [64], bacteria [4], fungi [163], and other organisms [163,164]. Taking biological extracts as ingredients, researchers have successfully synthesized some chemical pollution-free SeNPs that display diverse biological effects, such as UVB-induced DNA damage prevention [165] and cancer cells proliferating inhibition [126]. So far, bacteria are the most important source of biosynthesized SeNPs. Bacteria such as Bacillus licheniformis JS2 [127], Ochrobactrum sp. MPV1 [166], Streptomyces minutiscleroticus M10A62 [167], and Acinetobacter sp. SW30 [126] have been employed to fabricating SeNPs. These bacteria-based SeNPs are synthesized by culturing bacterial strain with sodium selenite (0.5-2 mM). Zonaro et al. [166] demonstrated that, under the stress of $\mathrm{Na}_{2} \mathrm{SeO}_{3}(0.5$ or $2 \mathrm{mM})$, Ochrobactrum sp. MPV1 was capable of converting selenite to elemental Se and synthesizing SeNPs intracellularly; however, medical applications of these SeNPs remain underexploited. The synthesizing protocol of bacteria-based SeNPs is now gradually developing; however, SeNPs should always be purified to avoid the toxicity caused by bacteria. Similar to bacteria, fungi with properties such as large output, easy accessibility, and economic feasibility could be used as candidates for biosynthesizing SeNPs [168]. However, the investigation into the practicability of fungi synthesized SeNPs in medical fields is relatively deficient. In Vetchinkina et al. [163], fungus-based spherical SeNPs were obtained from the medicinal basidiomycete Lentinula edodes cultured with inorganic selenium $\left(10^{-2} \mathrm{~mol}\right)$ or organoselenium $\left(10^{-7}\right.$ to $\left.10^{-3} \mathrm{~mol}\right)$. The reduction in selenium $\left(\mathrm{Se}^{\mathrm{IV}}\right.$ to $\left.\mathrm{Se}^{0}\right)$ was observed, and the synthesis mechanism of L. edodes based SeNPs was revealed by transmission electron microscopy, electron energy loss spectroscopy, and X-ray fluorescence [163]. Overall, bacteria and fungi are expected to be competent media for SeNPs assembling, given their capability of producing a hypotoxic form of Se by stepwise transforming Se oxyanions to elemental Se $[169,170]$. Intracellular synthesis of SeNPs could be achieved under ideal experimental conditions that usually require Se-involved culture [171], so that Se oxyanions would be transported into cells for downstream reduction and reassembly. In a study carried out by Sonkusre et al. [127], SeNPs synthesized in Bacillus licheniformis strain JS2 were able to initiate necroptosis in PC-3 cell by the ROS-mediated activation regulated by a RIP1 kinase, thus taken as undeveloped anti-cancer substances with high producing efficiency. Plant-based SeNPs are another interesting aspect of biosynthetic SeNPs [168]. For instance, Sharma 
et al. [64] synthesized selenium nanoballs with uniform size $(3-18 \mathrm{~nm})$ and shape using dried Vitis vinifera (raisin) extracts and selenous acid, with a simple refluxing method. Although the extract mechanism of plant-based SeNPs and the pharmaceutical applications remain largely underexplored, SeNPs synthesized with/in plants are likely to have vast potential for future development due to the variety of plants and their cleanliness.

As for the physically synthesized functional SeNPs, approaches such as pulsed laser ablation [172] and $\gamma$-radiation [173] have been used for their generation. For instance, Guisbiers et al. [174] obtained pure SeNPs by pulsed laser ablation in liquids and showed that these SeNPs were able to disturb the biofilm formation of a human pathogen Candida albicans, highlighting the potential for medical application of physical synthesis SeNPs. However, the application of physical-synthetic SeNPs in cancer treatment and prevention is still immature, which may be due to the equipment requirements.

From the above and Tables 1-4, SeNPs have great potential not only in cancer treatment but also as diagnostic/imaging agents and more. Among all, the chemotherapeutic effects of SeNPs could be easily considered the most promising application of SeNPs. So far, results from laboratories regarding the anticancer property of SeNPs have mainly been positive. SeNPs showed anticancer effects in a range of cancers, including hepatocarcinoma $[128,140]$, breast cancer $[122,129,141]$, colon adenocarcinoma [124,132], lymphoma [133], esophageal cancer [143], prostate cancer [136,147], ovarian cancer [137], and glioma [148]. Further studies and clinical trials are needed to elucidate the possible applications of SeNPs in oncology. Also, concerns such as toxicity of nanoparticles accumulation in the human body and the environment should be cautiously addressed.

\section{Se and Epigenetics: Possible Roles in Cancer Prevention and Therapy}

Epigenetic refers to the study of heritable changes in gene expression that do not involve changes to the underlying DNA sequence [1,75]. These changes are controlled by epigenetic factors such as epimodifications of DNA, post-translational modification (PTM) of histone, and expression of non-coding RNA (ncRNA) [1]. Epigenetics plays a vital role in cancer development, and currently, therapy targeting epigenetic changes is considered one of the most promising approaches in cancer treatment $[175,176]$. The epigenetic effects of Se and their implications for human health, including cancer, have been reviewed $[1,177,178]$. Studies have revealed that Se and Se compounds could affect the epigenome of a cell through all three major epigenetic controls: DNA methylation, histone modifications, and ncRNA expression [1]. In regards to cancer therapy, inorganic and organic Se compounds, such as MSA, SeMet, MSC, Se-allylselenocysteine, and selenite, could effectively inhibit the activities of histone deacetylases and DNA methyltransferases, which expressions are usually up-regulated in various types of cancer cells [179-182]. Notably, the epigenetic inhibition mechanisms of Se compounds appear to be quite distinctive depending on their chemical forms [180,183]. A genome-wide epigenetic analysis indicated that both inorganic (selenite) and organic (MSA) Se could epigenetically affect distinct gene sets in human chronic myeloid leukemia K562 cells: selenite affected genes involved in response to oxygen and hypoxia, whereas MSA affected genes associated with cell adhesion and glucocorticoid receptors [184]. So far, the epigenetic effects of SeNPs and mechanism of their action on gene expression remain largely unknown.

\section{Other Potential Applications of Se Compounds}

Se is an essential trace element required for the maintenance of human health. In addition to its potential roles and use in cancer prevention and therapy, Se compounds have many other useful non-cancer-related features. Among them, one of the most interesting features of Se is the antimicrobial and antiviral activity observed in specific Se compounds. Previous studies demonstrated the relationship between selenocompounds and the immune system and showed that Se supplementation could enhance the activity and cytotoxic response of NK cells [6-8,38,81]. Specifically, sufficient intake of dietary Se is crucial for handling viral infections and for preventing Se deficiency-related diseases caused by bacteria and viruses (e.g., Keshan disease) $[6,18]$. Researchers have also discovered the 
antibacterial, antifungal, and antiviral properties of SeNPs, and have demonstrated how SeNPs can be potentially used in various settings $[168,185,186]$. For example, Nguyen et al. [63] examined the antimicrobial activity of SeNPs against foodborne pathogens and indicated the possible use of SeNPs for food safety applications. Overall, it is anticipated that new and novel applications of Se compounds in various fields of life sciences will be extensively investigated and explored due to rapid advancement in nanotechnology and further understanding of the mechanisms underlying Se compounds at the nano-scale level.

\section{Conclusions}

Although several clinical trials indicated no significant benefit of Se in preventing cancer, overwhelming evidence has demonstrated that Se and many Se compounds, under certain circumstances, are potent anticancer agents. In vivo and in vitro studies have hinted that the Se compounds exert their anticancer ability through multiple mechanisms. However, further research and clinical trials are still required before these Se compounds can be clinically recognized as anticancer drugs. In addition to cancer therapy, Se compounds have been proven to be quite useful in other cancer-related fields such as chemoprevention, diagnosis, and imaging, as well as in non-cancer-related fields as described in this review and summarized in Tables 1-4. Among the Se compounds, SeNPs, as the emerging form of Se species, have attracted considerable attention. Judging from the current positive results of SeNPs against a range of cancers, SeNPs will play more critical roles in cancer prevention and therapy in the near future, especially in the era of precision medicine, where patients are provided with personalized and tailored treatment based on individual conditions and needs [75]. To conclude, in order to fully determine the potential of Se compounds, in particular the SeNPs, in cancer prevention and therapy, extensive further studies are required to better understand the underlying mechanisms behind the biophysiological effects of Se.

Author Contributions: Writing-Original Draft Preparation, H.W.T., H.-Y.M., A.T.Y.L., Y.-M.X.; Writing一Review and Editing, H.W.T., H.-Y.M., A.T.Y.L., Y.-M.X.; Supervision, A.T.Y.L., Y.-M.X.; Funding Acquisition, A.T.Y.L., Y.-M.X.

Funding: This work was supported by the grants from the National Natural Science Foundation of China (No. 31271445 and 31771582), the Science and Technology Planning Project of Guangdong Province of China (No. 2016A020215144), the Guangdong Natural Science Foundation of China (No. 2017A030313131), the "Thousand, Hundred, and Ten" project of the Department of Education of Guangdong Province of China (No. 124), the Basic and Applied Research Major Projects of Guangdong Province of China (2017KZDXM035), the Colleges and Universities Innovation Project of Guangdong Province of China (No. 2016KTSCX041 and 2016KTSCX042), and the "Yang Fan" Project of Guangdong Province of China (A.T.Y.L.-2016; Y.-M.X.-2015).

Acknowledgments: We would like to thank members of the Lau and $\mathrm{Xu}$ laboratory for critical review of this manuscript.

Conflicts of Interest: The authors declare no conflict of interest.

\section{Abbreviations}

$\begin{array}{ll}\text { D-501036 } & \text { 2,5-bis(5-hydroxymethyl-2-selenienyl)-3-hydroxymethyl- } N \text {-methylpyrrole } \\ \text { MSA } & \text { Methylseleninic acid } \\ \text { MSC } & \text { Methylselenocysteine } \\ \text { ncRNA } & \text { non-coding RNA } \\ \text { NK } & \text { Natural killer } \\ \text { NPC } & \text { Nutritional prevention of cancer } \\ \text { PBM } & \text { Peripheral blood mononuclear } \\ \text { PTM } & \text { Post-translational modification } \\ \text { ROS } & \text { Reactive oxygen species } \\ \text { Se } & \text { Selenium } \\ \text { SELECT } & \text { Selenium and vitamin E cancer prevention trial } \\ \text { SeMet } & \text { Selenomethionine } \\ \text { SeNPs } & \text { Se-containing nanoparticles } \\ \text { SWOG } & \text { Southwest Oncology Group }\end{array}$




\section{References}

1. Lau, A.T.Y.; Tan, H.W.; Xu, Y.M. Epigenetic effects of dietary trace elements. Curr. Pharmacol. Rep. 2017, 3, 232-241. [CrossRef]

2. Wu, Q.; Rayman, M.P.; Lv, H.; Schomburg, L.; Cui, B.; Gao, C.; Chen, P.; Zhuang, G.; Zhang, Z.; Peng, X.; et al. Low population selenium status is associated with increased prevalence of thyroid disease. J. Clin. Endocrinol. Metab. 2015, 100, 4037-4047. [CrossRef] [PubMed]

3. Li, Y.; Li, X.; Wong, Y.S.; Chen, T.; Zhang, H.; Liu, C.; Zheng, W. The reversal of cisplatin-induced nephrotoxicity by selenium nanoparticles functionalized with 11-mercapto-1-undecanol by inhibition of ROS-mediated apoptosis. Biomaterials 2011, 32, 9068-9076. [CrossRef] [PubMed]

4. Forootanfar, H.; Adeli-Sardou, M.; Nikkhoo, M.; Mehrabani, M.; Amir-Heidari, B.; Shahverdi, A.R.; Shakibaie, M. Antioxidant and cytotoxic effect of biologically synthesized selenium nanoparticles in comparison to selenium dioxide. J. Trace Elem. Med. Biol. 2014, 28, 75-79. [CrossRef] [PubMed]

5. Xiao, Y.; Huang, Q.; Zheng, Z.; Guan, H.; Liu, S. Construction of a Cordyceps sinensis exopolysaccharideconjugated selenium nanoparticles and enhancement of their antioxidant activities. Int. J. Biol. Macromol. 2017, 99, 483-491. [CrossRef]

6. Broome, C.S.; McArdle, F.; Kyle, J.A.; Andrews, F.; Lowe, N.M.; Hart, C.A.; Arthur, J.R.; Jackson, M.J. An increase in selenium intake improves immune function and poliovirus handling in adults with marginal selenium status. Am. J. Clin. Nutr. 2004, 80, 154-162. [CrossRef] [PubMed]

7. Narayan, V.; Ravindra, K.C.; Liao, C.; Kaushal, N.; Carlson, B.A.; Prabhu, K.S. Epigenetic regulation of inflammatory gene expression in macrophages by selenium. J. Nutr. Biochem. 2015, 26, 138-145. [CrossRef]

8. Wu, F.; Cao, W.; Xu, H.; Zhu, M.; Wang, J.; Ke, X. Treatment with a selenium-platinum compound induced T-cell acute lymphoblastic leukemia/lymphoma cells apoptosis through the mitochondrial signaling pathway. Oncol. Lett. 2017, 13, 1702-1710. [CrossRef]

9. Kohler, L.N.; Florea, A.; Kelley, C.P.; Chow, S.; Hsu, P.; Batai, K.; Saboda, K.; Lance, P.; Jacobs, E.T. Higher plasma selenium concentrations are associated with increased odds of prevalent type 2 diabetes. J. Nutr. 2018, 148, 1333-1340. [CrossRef]

10. Casaril, A.M.; Ignasiak, M.T.; Chuang, C.Y.; Vieira, B.; Padilha, N.B.; Carroll, L.; Lenardao, E.J.; Savegnago, L.; Davies, M.J. Selenium-containing indolyl compounds: Kinetics of reaction with inflammation-associated oxidants and protective effect against oxidation of extracellular matrix proteins. Free Radic. Biol. Med. 2017, 113, 395-405. [CrossRef]

11. Mistry, H.D.; Broughton Pipkin, F.; Redman, C.W.; Poston, L. Selenium in reproductive health. Am. J. Obstet. Gynecol. 2012, 206, 21-30. [CrossRef] [PubMed]

12. Riaz, M.; Mahmood, Z.; Shahid, M.; Saeed, M.U.; Tahir, I.M.; Shah, S.A.; Munir, N.; El-Ghorab, A. Impact of reactive oxygen species on antioxidant capacity of male reproductive system. Int. J. Immunopathol. Pharmacol. 2016, 29, 421-425. [CrossRef] [PubMed]

13. Gao, S.; Jin, Y.; Hall, K.S.; Liang, C.; Unverzagt, F.W.; Ji, R.; Murrell, J.R.; Cao, J.; Shen, J.; Ma, F.; et al. Selenium level and cognitive function in rural elderly Chinese. Am. J. Epidemiol. 2007, 165, 955-965. [CrossRef] [PubMed]

14. Jin, N.; Zhu, H.; Liang, X.; Huang, W.; Xie, Q.; Xiao, P.; Ni, J.; Liu, Q. Sodium selenate activated Wnt/ $\beta$-catenin signaling and repressed amyloid- $\beta$ formation in a triple transgenic mouse model of Alzheimer's disease. Exp. Neurol. 2017, 297, 36-49. [CrossRef] [PubMed]

15. Skröder, H.; Kippler, M.; Tofail, F.; Vahter, M. Early-life selenium status and cognitive function at 5 and 10 years of age in Bangladeshi children. Environ Health Perspect 2017, 125, 117003. [CrossRef] [PubMed]

16. Vinceti, M.; Filippini, T.; Cilloni, S.; Bargellini, A.; Vergoni, A.V.; Tsatsakis, A.; Ferrante, M. Health risk assessment of environmental selenium: Emerging evidence and challenges. Mol. Med. Rep. 2017, 15, 3323-3335. [CrossRef] [PubMed]

17. Vinceti, M.; Wei, E.T.; Malagoli, C.; Bergomi, M.; Vivoli, G. Adverse health effects of selenium in humans. Rev. Environ. Health 2001, 16, 233-251. [CrossRef] [PubMed]

18. Loscalzo, J. Keshan disease, selenium deficiency, and the selenoproteome. N. Engl. J. Med. 2014, 370, 1756-1760. [CrossRef] 
19. Yang, B.; Wang, K.; Zhang, D.; Sun, B.; Ji, B.; Wei, L.; Li, Z.; Wang, M.; Zhang, X.; Zhang, H.; et al. Light-activatable dual-source ROS-responsive prodrug nanoplatform for synergistic chemo-photodynamic therapy. Biomater. Sci. 2018, 6, 2965-2975. [CrossRef]

20. Sutter, M.E.; Thomas, J.D.; Brown, J.; Morgan, B. Selenium toxicity: A case of selenosis caused by a nutritional supplement. Ann. Intern. Med. 2008, 148, 970-971. [CrossRef]

21. Institute of Medicine (US) Panel on Dietary Antioxidants and Related Compounds. Dietary Reference Intakes for Vitamin C, Vitamin E, Selenium, and Carotenoids; National Academy Press: Washington, DC, USA, 2000; pp. 284-324.

22. Weisberger, A.S.; Suhrland, L.G. Studies on analogues of L-cysteine and L-cystine. II. The effect of selenium cystine on Murphy lymphosarcoma tumor cells in the rat. Blood 1956, 11, 11-18. [PubMed]

23. Weisberger, A.S.; Suhrland, L.G. Studies on analogues of L-cysteine and L-cystine. III. The effect of selenium cystine on leukemia. Blood 1956, 11, 19-30. [PubMed]

24. Mautner, H.G.; Jaffe, J.J. The activity of 6-selenopurine and related compounds against some experimental mouse tumors. Cancer Res. 1958, 18, 294-298. [PubMed]

25. Weekley, C.M.; Harris, H.H. Which form is that? The importance of selenium speciation and metabolism in the prevention and treatment of disease. Chem. Soc. Rev. 2013, 42, 8870-8894. [CrossRef] [PubMed]

26. Misra, S.; Boylan, M.; Selvam, A.; Spallholz, J.E.; Bjornstedt, M. Redox-active selenium compounds-from toxicity and cell death to cancer treatment. Nutrients 2015, 7, 3536-3556. [CrossRef] [PubMed]

27. Clark, L.C.; Combs, G.F., Jr.; Turnbull, B.W.; Slate, E.H.; Chalker, D.K.; Chow, J.; Davis, L.S.; Glover, R.A.; Graham, G.F.; Gross, E.G.; et al. Effects of selenium supplementation for cancer prevention in patients with carcinoma of the skin. A randomized controlled trial. Nutritional Prevention of Cancer Study Group. JAMA 1996, 276, 1957-1963. [CrossRef] [PubMed]

28. Clark, L.C.; Dalkin, B.; Krongrad, A.; Combs, G.F., Jr.; Turnbull, B.W.; Slate, E.H.; Witherington, R.; Herlong, J.H.; Janosko, E.; Carpenter, D.; et al. Decreased incidence of prostate cancer with selenium supplementation: Results of a double-blind cancer prevention trial. Br. J. Urol. 1998, 81, 730-734. [CrossRef] [PubMed]

29. Duffield-Lillico, A.J.; Reid, M.E.; Turnbull, B.W.; Combs, G.F., Jr.; Slate, E.H.; Fischbach, L.A.; Marshall, J.R.; Clark, L.C. Baseline characteristics and the effect of selenium supplementation on cancer incidence in a randomized clinical trial: A summary report of the Nutritional Prevention of Cancer Trial. Cancer Epidemiol. Biomarkers Prev. 2002, 11, 630-639. [PubMed]

30. Vinceti, M.; Filippini, T.; Cilloni, S.; Crespi, C.M. The epidemiology of selenium and human cancer. Adv. Cancer Res. 2017, 136, 1-48.

31. Collery, P. Strategies for the development of selenium-based anticancer drugs. J. Trace Elem. Med. Biol. 2018, 50, 498-507. [CrossRef]

32. Lippman, S.M.; Klein, E.A.; Goodman, P.J.; Lucia, M.S.; Thompson, I.M.; Ford, L.G.; Parnes, H.L.; Minasian, L.M.; Gaziano, J.M.; Hartline, J.A.; et al. Effect of selenium and vitamin E on risk of prostate cancer and other cancers: The Selenium and Vitamin E Cancer Prevention Trial (SELECT). JAMA 2009, 301, 39-51. [CrossRef] [PubMed]

33. Marshall, J.R.; Tangen, C.M.; Sakr, W.A.; Wood, D.P., Jr.; Berry, D.L.; Klein, E.A.; Lippman, S.M.; Parnes, H.L.; Alberts, D.S.; Jarrard, D.F.; et al. Phase III trial of selenium to prevent prostate cancer in men with high-grade prostatic intraepithelial neoplasia: SWOG S9917. Cancer Prev. Res. 2011, 4, 1761-1769. [CrossRef] [PubMed]

34. Karp, D.D.; Lee, S.J.; Keller, S.M.; Wright, G.S.; Aisner, S.; Belinsky, S.A.; Johnson, D.H.; Johnston, M.R.; Goodman, G.; Clamon, G.; et al. Randomized, double-blind, placebo-controlled, phase III chemoprevention trial of selenium supplementation in patients with resected stage I non-small-cell lung cancer: ECOG 5597. J. Clin. Oncol. 2013, 31, 4179-4187. [CrossRef] [PubMed]

35. Mix, M.; Singh, A.K.; Tills, M.; Dibaj, S.; Groman, A.; Jaggernauth, W.; Rustum, R.; Jameson, M.B. Randomized phase II trial of selenomethionine as a modulator of efficacy and toxicity of chemoradiation in squamous cell carcinoma of the head and neck. World J. Clin. Oncol. 2015, 6, 166. [CrossRef] [PubMed]

36. Vinceti, M.; Vicentini, M.; Wise, L.A.; Sacchettini, C.; Malagoli, C.; Ballotari, P.; Filippini, T.; Malavolti, M.; Rossi, P.G. Cancer incidence following long-term consumption of drinking water with high inorganic selenium content. Sci. Total Environ. 2018, 635, 390-396. [CrossRef] [PubMed]

37. Akbaraly, N.T.; Arnaud, J.; Hininger-Favier, I.; Gourlet, V.; Roussel, A.M.; Berr, C. Selenium and mortality in the elderly: Results from the EVA study. Clin. Chem. 2005, 51, 2117-2123. [CrossRef] [PubMed] 
38. Fernandes, A.P.; Gandin, V. Selenium compounds as therapeutic agents in cancer. Biochim. Biophys. Acta 2015, 1850, 1642-1660. [CrossRef]

39. Rahmanto, A.S.; Davies, M.J. Selenium-containing amino acids as direct and indirect antioxidants. IUBMB Life 2012, 64, 863-871. [CrossRef]

40. Prasad, S.; Gupta, S.C.; Tyagi, A.K. Reactive oxygen species (ROS) and cancer: Role of antioxidative nutraceuticals. Cancer Lett. 2017, 387, 95-105. [CrossRef]

41. Georgieva, E.; Ivanova, D.; Zhelev, Z.; Bakalova, R.; Gulubova, M.; Aoki, I. Mitochondrial dysfunction and redox imbalance as a diagnostic marker of "free radical diseases". Anticancer Res. 2017, 37, 5373-5381.

42. Valko, M.; Rhodes, C.J.; Moncol, J.; Izakovic, M.; Mazur, M. Free radicals, metals and antioxidants in oxidative stress-induced cancer. Chem. Biol. Interact. 2006, 160, 1-40. [CrossRef] [PubMed]

43. Drake, E.N. Cancer chemoprevention: Selenium as a prooxidant, not an antioxidant. Med. Hypotheses 2006, 67, 318-322. [CrossRef] [PubMed]

44. Hatfield, D.L.; Yoo, M.H.; Carlson, B.A.; Gladyshev, V.N. Selenoproteins that function in cancer prevention and promotion. Biochim. Biophys. Acta 2009, 1790, 1541-1545. [CrossRef]

45. Brozmanová, J.; Mániková, D.; Vlčková, V.; Chovanec, M. Selenium: A double-edged sword for defense and offence in cancer. Arch. Toxicol. 2010, 84, 919-938. [CrossRef] [PubMed]

46. Brigelius-Flohé, R.; Flohé, L. Selenium and redox signaling. Arch. Biochem. Biophys. 2017, 617, 48-59. [CrossRef] [PubMed]

47. Varlamova, E.G.; Cheremushkina, I.V. Contribution of mammalian selenocysteine-containing proteins to carcinogenesis. J. Trace Elem. Med. Biol. 2017, 39, 76-85. [CrossRef] [PubMed]

48. Li, T.; Kang, G.; Wang, T.; Huang, H. Tumor angiogenesis and anti-angiogenic gene therapy for cancer. Oncol. Lett. 2018, 16, 687-702. [CrossRef] [PubMed]

49. Unni, E.; Koul, D.; Yung, W.K.; Sinha, R. Se-methylselenocysteine inhibits phosphatidylinositol 3-kinase activity of mouse mammary epithelial tumor cells in vitro. Breast Cancer Res. 2005, 7, R699-R707. [CrossRef] [PubMed]

50. Schroterova, L.; Kralova, V.; Voracova, A.; Haskova, P.; Rudolf, E.; Cervinka, M. Antiproliferative effects of selenium compounds in colon cancer cells: Comparison of different cytotoxicity assays. Toxicol. In Vitro 2009, 23, 1406-1411. [CrossRef] [PubMed]

51. Suzuki, M.; Endo, M.; Shinohara, F.; Echigo, S.; Rikiishi, H. Differential apoptotic response of human cancer cells to organoselenium compounds. Cancer Chemother. Pharmacol. 2010, 66, 475-484. [CrossRef]

52. Cao, S.; Durrani, F.A.; Rustum, Y.M. Selective modulation of the therapeutic efficacy of anticancer drugs by selenium containing compounds against human tumor xenografts. Clin. Cancer Res. 2004, 10, 2561-2569. [CrossRef] [PubMed]

53. Li, Z.; Carrier, L.; Belame, A.; Thiyagarajah, A.; Salvo, V.A.; Burow, M.E.; Rowan, B.G. Combination of methylselenocysteine with tamoxifen inhibits MCF-7 breast cancer xenografts in nude mice through elevated apoptosis and reduced angiogenesis. Breast Cancer Res. Treat. 2009, 118, 33-43. [CrossRef] [PubMed]

54. Chintala, S.; Toth, K.; Cao, S.; Durrani, F.A.; Vaughan, M.M.; Jensen, R.L.; Rustum, Y.M. Se-methylselenocysteine sensitizes hypoxic tumor cells to irinotecan by targeting hypoxia-inducible factor 1 $\alpha$. Cancer Chemother. Pharmacol. 2010, 66, 899-911. [CrossRef] [PubMed]

55. Bhattacharya, A. Methylselenocysteine: A promising antiangiogenic agent for overcoming drug delivery barriers in solid malignancies for therapeutic synergy with anticancer drugs. Expert. Opin. Drug Deliv. 2011, 8, 749-763. [CrossRef] [PubMed]

56. Cao, S.; Durrani, F.A.; Toth, K.; Rustum, Y.M. Se-methylselenocysteine offers selective protection against toxicity and potentiates the antitumour activity of anticancer drugs in preclinical animal models. Br. J. Cancer 2014, 110, 1733-1743. [CrossRef] [PubMed]

57. McAuslan, B.R.; Reilly, W. Selenium-induced cell migration and proliferation: Relevance to angiogenesis and microangiopathy. Microvasc. Res. 1986, 32, 112-120. [CrossRef]

58. Streicher, K.L.; Sylte, M.J.; Johnson, S.E.; Sordillo, L.M. Thioredoxin reductase regulates angiogenesis by increasing endothelial cell-derived vascular endothelial growth factor. Nutr. Cancer 2004, 50, 221-231. [CrossRef]

59. Zhang, J.; Wang, H.; Yan, X.; Zhang, L. Comparison of short-term toxicity between Nano-Se and selenite in mice. Life Sci. 2005, 76, 1099-1109. [CrossRef] 
60. Zhang, J.; Wang, X.; Xu, T. Elemental selenium at nano size (Nano-Se) as a potential chemopreventive agent with reduced risk of selenium toxicity: Comparison with Se-methylselenocysteine in mice. Toxicol. Sci. 2008, 101, 22-31. [CrossRef]

61. Chaudhary, S.; Umar, A.; Mehta, S.K. Surface functionalized selenium nanoparticles for biomedical applications. J. Biomed. Nanotechnol. 2014, 10, 3004-3042. [CrossRef]

62. Bai, K.; Hong, B.; He, J.; Hong, Z.; Tan, R. Preparation and antioxidant properties of selenium nanoparticles-loaded chitosan microspheres. Int. J. Nanomed. 2017, 12, 4527-4539. [CrossRef] [PubMed]

63. Nguyen, T.H.D.; Vardhanabhuti, B.; Lin, M.J.; Mustapha, A. Antibacterial properties of selenium nanoparticles and their toxicity to Caco-2 cells. Food Control 2017, 77, 17-24. [CrossRef]

64. Sharma, G.; Sharma, A.R.; Bhavesh, R.; Park, J.; Ganbold, B.; Nam, J.S.; Lee, S.S. Biomolecule-mediated synthesis of selenium nanoparticles using dried Vitis vinifera (raisin) extract. Molecules 2014, 19, 2761-2770. [CrossRef] [PubMed]

65. Fairweather-Tait, S.J.; Collings, R.; Hurst, R. Selenium bioavailability: Current knowledge and future research requirements. Am. J. Clin. Nutr. 2010, 91, 1484S-1491S. [CrossRef] [PubMed]

66. Rayman, M.P. Selenium in cancer prevention: A review of the evidence and mechanism of action. Proc. Nutr. Soc. 2005, 64, 527-542. [CrossRef] [PubMed]

67. Papp, L.V.; Lu, J.; Holmgren, A.; Khanna, K.K. From selenium to selenoproteins: Synthesis, identity, and their role in human health. Antioxid. Redox Signal. 2007, 9, 775-806. [CrossRef] [PubMed]

68. Jackson, M.I.; Combs, G.F., Jr. Selenium and anticarcinogenesis: Underlying mechanisms. Curr. Opin. Clin. Nutr. Metab. Care 2008, 11, 718-726. [CrossRef]

69. Ronai, Z.; Tillotson, J.K.; Traganos, F.; Darzynkiewicz, Z.; Conaway, C.C.; Upadhyaya, P.; el-Bayoumy, K. Effects of organic and inorganic selenium compounds on rat mammary tumor cells. Int. J. Cancer 1995, 63, 428-434. [CrossRef]

70. Sanmartín, C.; Plano, D.; Sharma, A.K.; Palop, J.A. Selenium compounds, apoptosis and other types of cell death: An overview for cancer therapy. Int. J. Mol. Sci. 2012, 13, 9649-9672. [CrossRef]

71. Choi, A.; Jo, M.J.; Jung, M.J.; Kim, H.S.; Yoon, S. Selenate specifically sensitizes drug-resistant cancer cells by increasing apoptosis via G2 phase cell cycle arrest without P-GP inhibition. Eur. J. Pharmacol. 2015, 764, 63-69. [CrossRef]

72. Takahashi, M.; Sato, T.; Shinohara, F.; Echigo, S.; Rikiishi, H. Possible role of glutathione in mitochondrial apoptosis of human oral squamous cell carcinoma caused by inorganic selenium compounds. Int. J. Oncol. 2005, 27, 489-495. [CrossRef] [PubMed]

73. Endo, M.; Hasegawa, H.; Kaneko, T.; Kanno, C.; Monma, T.; Kano, M.; Shinohara, F.; Takahashi, T. Antitumor activity of selenium compounds and its underlying mechanism in human oral squamous cell carcinoma cells: A preliminary study. J. Oral Maxillofac. Surg. Med. Pathol. 2017, 29, 17-23. [CrossRef]

74. Kieliszek, M.; Lipinski, B.; Blazejak, S. Application of sodium selenite in the prevention and treatment of cancers. Cells 2017, 6, 39. [CrossRef]

75. Tan, H.W.; Xu, Y.M.; Wu, D.D.; Lau, A.T.Y. Recent insights into human bronchial proteomics - how are we progressing and what is next? Expert. Rev. Proteomics 2018, 15, 113-130. [CrossRef] [PubMed]

76. Brodin, O.; Eksborg, S.; Wallenberg, M.; Asker-Hagelberg, C.; Larsen, E.H.; Mohlkert, D.; Lenneby-Helleday, C.; Jacobsson, H.; Linder, S.; Misra, S.; et al. Pharmacokinetics and toxicity of sodium selenite in the treatment of patients with carcinoma in a phase I clinical trial: The SECAR Study. Nutrients 2015, 7, 4978-4994. [CrossRef] [PubMed]

77. Berthier, S.; Arnaud, J.; Champelovier, P.; Col, E.; Garrel, C.; Cottet, C.; Boutonnat, J.; Laporte, F.; Faure, P.; Hazane-Puch, F. Anticancer properties of sodium selenite in human glioblastoma cell cluster spheroids. J. Trace Elem. Med. Biol. 2017, 44, 161-176. [CrossRef]

78. Lipinski, B. Sodium selenite as an anticancer agent. Anticancer Agents Med. Chem. 2017, 17, 658-661. [CrossRef]

79. Chen, W.; An, J.; Guo, J.; Wu, Y.; Yang, L.; Dai, J.; Gong, K.; Miao, S.; Xi, S.; Du, J. Sodium selenite attenuates lung adenocarcinoma progression by repressing SOX2-mediated stemness. Cancer Chemother. Pharmacol. 2018, 81, 885-895. [CrossRef] [PubMed]

80. Olm, E.; Fernandes, A.P.; Hebert, C.; Rundlöf, A.K.; Larsen, E.H.; Danielsson, O.; Björnstedt, M. Extracellular thiol-assisted selenium uptake dependent on the $\mathrm{x}_{\mathrm{C}}{ }^{-}$cystine transporter explains the cancer-specific cytotoxicity of selenite. PNAS 2009, 106, 11400-11405. [CrossRef] [PubMed] 
81. Enqvist, M.; Nilsonne, G.; Hammarfjord, O.; Wallin, R.P.A.; Bjorkstrom, N.K.; Bjornstedt, M.; Hjerpe, A.; Ljunggren, H.G.; Dobra, K.; Malmberg, K.J.; et al. Selenite induces posttranscriptional blockade of HLA-E expression and sensitizes tumor cells to CD94/NKG2A-Positive NK Cells. J. Immunol. 2011, 187, 3546-3554. [CrossRef]

82. Rigobello, M.P.; Gandin, V.; Folda, A.; Rundlof, A.K.; Fernandes, A.P.; Bindoli, A.; Marzano, C.; Bjornstedt, M. Treatment of human cancer cells with selenite or tellurite in combination with auranofin enhances cell death due to redox shift. Free Radic. Biol. Med. 2009, 47, 710-721. [CrossRef] [PubMed]

83. Zheng, X.; Xu, W.; Sun, R.; Yin, H.; Dong, C.; Zeng, H. Synergism between thioredoxin reductase inhibitor ethaselen and sodium selenite in inhibiting proliferation and inducing death of human non-small cell lung cancer cells. Chem. Biol. Interact. 2017, 275, 74-85. [CrossRef] [PubMed]

84. Li, J.; Sun, K.; Ni, L.; Wang, X.; Wang, D.; Zhang, J. Sodium selenosulfate at an innocuous dose markedly prevents cisplatin-induced gastrointestinal toxicity. Toxicol. Appl. Pharmacol. 2012, 258, 376-383. [CrossRef] [PubMed]

85. Freitas, M.; Alves, V.; Sarmento-Ribeiro, A.B.; Mota-Pinto, A. Combined effect of sodium selenite and docetaxel on PC3 metastatic prostate cancer cell line. Biochem. Biophys. Res. Commun. 2011, 408, 713-719. [CrossRef] [PubMed]

86. Schroeder, C.P.; Goeldner, E.M.; Schulze-Forster, K.; Eickhoff, C.A.; Holtermann, P.; Heidecke, H. Effect of selenite combined with chemotherapeutic agents on the proliferation of human carcinoma cell lines. Biol. Trace Elem. Res. 2004, 99, 17-25. [CrossRef]

87. Björkhem-Bergman, L.; Jönsson, K.; Eriksson, L.C.; Olsson, J.M.; Lehmann, S.; Paul, C.; Björnstedt, M. Drug-resistant human lung cancer cells are more sensitive to selenium cytotoxicity. Effects on thioredoxin reductase and glutathione reductase. Biochem. Pharmacol. 2002, 63, 1875-1884. [CrossRef]

88. Jönsson-Videsäter, K.; Björkhem-Bergman, L.; Hossain, A.; Söderberg, A.; Eriksson, L.C.; Paul, C.; Rosén, A.; Björnstedt, M. Selenite-induced apoptosis in doxorubicin-resistant cells and effects on the thioredoxin system. Biochem. Pharmacol. 2004, 67, 513-522. [CrossRef]

89. Hinrichsen, S.; Planer-Friedrich, B. Cytotoxic activity of selenosulfate versus selenite in tumor cells depends on cell line and presence of amino acids. Environ. Sci. Pollut. Res. Int. 2016, 23, 8349-8357. [CrossRef]

90. Hu, B.; Cheng, R.; Gao, X.; Pan, X.; Kong, F.; Liu, X.; Xu, K.; Tang, B. Targetable mesoporous Silica nanoprobes for mapping the subcellular distribution of $\mathrm{H}_{2} \mathrm{Se}$ in cancer cells. ACS Appl. Mater. Interfaces 2018, 10, 17345-17351. [CrossRef]

91. Storkey, C.; Davies, M.J.; White, J.M.; Schiesser, C.H. Synthesis and antioxidant capacity of 5-selenopyranose derivatives. Chem. Commun. 2011, 47, 9693-9695. [CrossRef]

92. Jariwalla, R.J.; Gangapurkar, B.; Nakamura, D. Differential sensitivity of various human tumour-derived cell types to apoptosis by organic derivatives of selenium. Br. J. Nutr. 2009, 101, 182-189. [CrossRef] [PubMed]

93. Tung, Y.C.; Tsai, M.L.; Kuo, F.L.; Lai, C.S.; Badmaev, V.; Ho, C.T.; Pan, M.H. Se-Methyl-${ }_{-}{ }^{-}$selenocysteine induces apoptosis via endoplasmic reticulum stress and the death receptor pathway in human colon adenocarcinoma COLO 205 Cells. J. Agricult. Food Chem. 2015, 63, 5008-5016. [CrossRef] [PubMed]

94. Domracheva, I.; Kanepe-Lapsa, I.; Jackevica, L.; Vasiljeva, J.; Arsenyan, P. Selenopheno quinolinones and coumarins promote cancer cell apoptosis by ROS depletion and caspase-7 activation. Life Sci. 2017, 186, 92-101. [CrossRef] [PubMed]

95. Fan, C.; Zheng, W.; Fu, X.; Li, X.; Wong, Y.S.; Chen, T. Strategy to enhance the therapeutic effect of doxorubicin in human hepatocellular carcinoma by selenocystine, a synergistic agent that regulates the ROS-mediated signaling. Oncotarget 2014, 5, 2853-2863. [CrossRef] [PubMed]

96. Deepagan, V.G.; Kwon, S.; You, D.G.; Nguyen, V.Q.; Um, W.; Ko, H.; Lee, H.; Jo, D.G.; Kang, Y.M.; Park, J.H. In situ diselenide-crosslinked polymeric micelles for ROS-mediated anticancer drug delivery. Biomaterials 2016, 103, 56-66. [CrossRef] [PubMed]

97. Çetin, E.S.; Naziroğlu, M.; Çĭ̆, B.; Övey, I.S.; Koşar, P.A. Selenium potentiates the anticancer effect of cisplatin against oxidative stress and calcium ion signaling-induced intracellular toxicity in MCF-7 breast cancer cells: Involvement of the TRPV1 channel. J. Recept. Signal. Transduct. Res. 2017, 37, 84-93. [CrossRef] [PubMed]

98. Gandin, V.; Khalkar, P.; Braude, J.; Fernandes, A.P. Organic selenium compounds as potential chemotherapeutic agents for improved cancer treatment. Free Radic. Biol. Med. 2018, 127, 80-97. [CrossRef]

99. Álvarez-Pérez, M.; Ali, W.; Marć, M.A.; Handzlik, J.; Domínguez-Álvarez, E. Selenides and diselenides: A review of their anticancer and chemopreventive activity. Molecules 2018, 23, 628. [CrossRef] 
100. Ali, W.; Álvarez-Pérez, M.; Marć, M.A.; Salardón-Jiménez, N.; Handzlik, J.; Domínguez-Álvarez, E. The anticancer and chemopreventive activity of selenocyanate-containing compounds. Curr. Pharmacol. Rep. 2018, 4, 468-481. [CrossRef]

101. de Bruin, E.C.; Medema, J.P. Apoptosis and non-apoptotic deaths in cancer development and treatment response. Cancer Treat. Rev. 2008, 34, 737-749. [CrossRef]

102. Poerschke, R.L.; Franklin, M.R.; Moos, P.J. Modulation of redox status in human lung cell lines by organoselenocompounds: Selenazolidines, selenomethionine, and methylseleninic acid. Toxicol. In Vitro 2008, 22, 1761-1767. [CrossRef] [PubMed]

103. Gao, R.; Zhao, L.; Liu, X.; Rowan, B.G.; Wabitsch, M.; Edwards, D.P.; Nishi, Y.; Yanase, T.; Yu, Q.; Dong, Y. Methylseleninic acid is a novel suppressor of aromatase expression. J. Endocrinol. 2012, 212, 199-205. [CrossRef] [PubMed]

104. Qi, Y.; Fu, X.; Xiong, Z.; Zhang, H.; Hill, S.M.; Rowan, B.G.; Dong, Y. Methylseleninic acid enhances paclitaxel efficacy for the treatment of triple-negative breast cancer. PLOS ONE 2012, 7, e31539. [CrossRef] [PubMed]

105. Lennicke, C.; Rahn, J.; Bukur, J.; Hochgräfe, F.; Wessjohann, L.A.; Lichtenfels, R.; Seliger, B. Modulation of MHC class I surface expression in B16F10 melanoma cells by methylseleninic acid. Oncoimmunology 2017, 6, e1259049. [CrossRef] [PubMed]

106. Li, G.X.; Lee, H.J.; Wang, Z.; Hu, H.; Liao, J.D.; Watts, J.C.; Combs, G.F.; Lü, J. Superior in vivo inhibitory efficacy of methylseleninic acid against human prostate cancer over selenomethionine or selenite. Carcinogenesis 2008, 29, 1005-1012. [CrossRef] [PubMed]

107. Wang, L.; Bonorden, M.J.L.; Li, G.; Lee, H.J.; Hu, H.; Zhang, Y.; Liao, J.D.; Cleary, M.P.; Lü, J. Methyl-selenium compounds inhibit prostate carcinogenesis in the transgenic adenocarcinoma of mouse prostate model with survival benefit. Cancer Prev. Res. 2009, 2, 484-495. [CrossRef] [PubMed]

108. Lee, S.O.; Chun, J.Y.; Nadiminty, N.; Trump, D.L.; Ip, C.; Dong, Y.; Gao, A.C. Monomethylated selenium inhibits growth of LNCaP human prostate cancer xenograft accompanied by a decrease in the expression of androgen receptor and prostate-specific antigen (PSA). Prostate 2006, 66, 1070-1075. [CrossRef] [PubMed]

109. Lobb, R.J.; Jacobson, G.M.; Cursons, R.T.; Jameson, M.B. The interaction of selenium with chemotherapy and radiation on normal and malignant human mononuclear blood cells. Int. J. Mol. Sci. 2018, 19, 3167. [CrossRef] [PubMed]

110. Sun, L.; Zhang, J.; Yang, Q.; Si, Y.; Liu, Y.; Wang, Q.; Han, F.; Huang, Z. Synergistic effects of SAM and selenium compounds on proliferation, migration and adhesion of HeLa cells. Anticancer Res. 2017, 37, 4433-4441. [PubMed]

111. Li, Z.; Carrier, L.; Rowan, B.G. Methylseleninic acid synergizes with tamoxifen to induce caspase-mediated apoptosis in breast cancer cells. Mol. Cancer Ther. 2008, 7, 3056-3063. [CrossRef]

112. Khalkar, P.; Diaz-Argelich, N.; Antonio Palop, J.; Sanmartín, C.; Fernandes, A.P. Novel methylselenoesters induce programed cell death via entosis in pancreatic cancer cells. Int. J. Mol. Sci. 2018, 19, 2849. [CrossRef] [PubMed]

113. Shi, C.; Yu, L.; Yang, F.; Yan, J.; Zeng, H. A novel organoselenium compound induces cell cycle arrest and apoptosis in prostate cancer cell lines. Biochem. Biophys. Res. Commun. 2003, 309, 578-583. [CrossRef]

114. Sharma, V.; Tewari, R.; Sk, U.H.; Joseph, C.; Sen, E. Ebselen sensitizes glioblastoma cells to Tumor Necrosis Factor $(\mathrm{TNF} \alpha)$-induced apoptosis through two distinct pathways involving NF- $\kappa \beta$ downregulation and Fas-mediated formation of death inducing signaling complex. Int. J. Cancer 2008, 123, 2204-2212. [CrossRef] [PubMed]

115. Shiah, H.S.; Lee, W.S.; Juang, S.H.; Hong, P.C.; Lung, C.C.; Chang, C.J.; Chou, K.M.; Chang, J.Y. Mitochondria-mediated and p53-associated apoptosis induced in human cancer cells by a novel selenophene derivative, D-501036. Biochem. Pharmacol. 2007, 73, 610-619. [CrossRef] [PubMed]

116. Juang, S.H.; Lung, C.C.; Hsu, P.C.; Hsu, K.S.; Li, Y.C.; Hong, P.C.; Shiah, H.S.; Kuo, C.C.; Huang, C.W.; Wang, Y.C.; et al. D-501036, a novel selenophene-based triheterocycle derivative, exhibits potent in vitro and in vivo antitumoral activity which involves DNA damage and ataxia telangiectasia-mutated nuclear protein kinase activation. Mol. Cancer Ther. 2007, 6, 193-202. [CrossRef] [PubMed]

117. Yang, Y.N.; Chou, K.M.; Pan, W.Y.; Chen, Y.W.; Tsou, T.C.; Yeh, S.C.; Cheung, C.H.; Chen, L.T.; Chang, J.Y. Enhancement of non-homologous end joining DNA repair capacity confers cancer cells resistance to the novel selenophene compound, D-501036. Cancer Lett. 2011, 309, 110-118. [CrossRef] 
118. Gumulec, J.; Balvan, J.; Sztalmachova, M.; Raudenska, M.; Dvorakova, V.; Knopfova, L.; Polanska, H.; Hudcova, K.; Ruttkay-Nedecky, B.; Babula, P.; et al. Cisplatin-resistant prostate cancer model: Differences in antioxidant system, apoptosis and cell cycle. Int. J. Oncol. 2014, 44, 923-933. [CrossRef]

119. Bartolini, D.; Sancineto, L.; Fabro de Bem, A.; Tew, K.D.; Santi, C.; Radi, R.; Toquato, P.; Galli, F. Selenocompounds in cancer therapy: An overview. Adv. Cancer Res. 2017, 136, 259-302.

120. Ho, B.N.; Pfeffer, C.M.; Singh, A.T.K. Update on nanotechnology-based drug delivery systems in cancer treatment. Anticancer Res. 2017, 37, 5975-5981.

121. Gao, F.; Yuan, Q.; Gao, L.; Cai, P.; Zhu, H.; Liu, R.; Wang, Y.; Wei, Y.; Huang, G.; Liang, J.; et al. Cytotoxicity and therapeutic effect of irinotecan combined with selenium nanoparticles. Biomaterials 2014, 35, 8854-8866. [CrossRef]

122. Shamsi, M.M.; Chekachak, S.; Soudi, S.; Gharakhanlou, R.; Quinn, L.S.; Ranjbar, K.; Rezaei, S.; Shirazi, F.J.; Allahmoradi, B.; Yazdi, M.H.; et al. Effects of exercise training and supplementation with selenium nanoparticle on T-helper 1 and 2 and cytokine levels in tumor tissue of mice bearing the 4 T1 mammary carcinoma. Nutrition 2018, 57, 141-147. [CrossRef] [PubMed]

123. Skalickova, S.; Milosavljevic, V.; Cihalova, K.; Horky, P.; Richtera, L.; Adam, V. Selenium nanoparticles as a nutritional supplement. Nutrition 2017, 33, 83-90. [CrossRef] [PubMed]

124. Zhang, J.; Teng, Z.; Yuan, Y.; Zeng, Q.Z.; Lou, Z.; Lee, S.H.; Wang, Q. Development, physicochemical characterization and cytotoxicity of selenium nanoparticles stabilized by beta-lactoglobulin. Int. J. Biol. Macromol. 2018, 107, 1406-1413. [CrossRef] [PubMed]

125. Menon, S.; KS, S.D.; Santhiya, R.; Rajeshkumar, S.; Kumar, V. Selenium nanoparticles: A potent chemotherapeutic agent and an elucidation of its mechanism. Colloids Surf B Biointerfaces 2018, 170, 280-292. [CrossRef] [PubMed]

126. Wadhwani, S.A.; Gorain, M.; Banerjee, P.; Shedbalkar, U.U.; Singh, R.; Kundu, G.C.; Chopade, B.A. Green synthesis of selenium nanoparticles using Acinetobacter sp. SW30: Optimization, characterization and its anticancer activity in breast cancer cells. Int. J. Nanomed. 2017, 12, 6841-6855. [CrossRef] [PubMed]

127. Sonkusre, P.; Cameotra, S.S. Biogenic selenium nanoparticles induce ROS-mediated necroptosis in PC-3 cancer cells through TNF activation. J. Nanobiotechnol. 2017, 15, 1-12. [CrossRef] [PubMed]

128. Cui, D.; Yan, C.; Miao, J.; Zhang, X.; Chen, J.; Sun, L.; Meng, L.; Liang, T.; Li, Q. Synthesis, characterization and antitumor properties of selenium nanoparticles coupling with ferulic acid. Mater. Sci. Eng. C 2018, 90, 104-112. [CrossRef] [PubMed]

129. Shahverdi, A.R.; Shahverdi, F.; Faghfuri, E.; Reza Khoshayand, M.; Mavandadnejad, F.; Yazdi, M.H.; Amini, M. Characterization of folic acid surface-coated selenium nanoparticles and corresponding in vitro and in vivo effects against breast cancer. Arch. Med. Res. 2018, 49, 10-17. [CrossRef]

130. Yang, Y.; Xie, Q.; Zhao, Z.; He, L.; Chan, L.; Liu, Y.; Chen, Y.; Bai, M.; Pan, T.; Qu, Y.; et al. Functionalized selenium nanosystem as radiation sensitizer of ${ }^{125}$ I seeds for precise cancer therapy. ACS Appl. Mater. Interfaces 2017, 9, 25857-25869. [CrossRef]

131. Qiu, W.Y.; Wang, Y.Y.; Wang, M.; Yan, J.K. Construction, stability, and enhanced antioxidant activity of pectin-decorated selenium nanoparticles. Colloids Surf. B Biointerfaces 2018, 170, 692-700. [CrossRef]

132. Huang, G.; Liu, Z.; He, L.; Luk, K.H.; Cheung, S.T.; Wong, K.H.; Chen, T. Autophagy is an important action mode for functionalized selenium nanoparticles to exhibit anti-colorectal cancer activity. Biomater. Sci. 2018, 6, 2508-2517. [CrossRef] [PubMed]

133. Gautam, P.K.; Kumar, S.; Tomar, M.S.; Singh, R.K.; Acharya, A.; Kumar, S.; Ram, B. Selenium nanoparticles induce suppressed function of tumor associated macrophages and inhibit Dalton's lymphoma proliferation. Biochem. Biophys. Rep. 2017, 12, 172-184. [PubMed]

134. Zhao, G.; Wu, X.; Chen, P.; Zhang, L.; Yang, C.S.; Zhang, J. Selenium nanoparticles are more efficient than sodium selenite in producing reactive oxygen species and hyper-accumulation of selenium nanoparticles in cancer cells generates potent therapeutic effects. Free Radic. Biol. Med. 2018, 126, 55-66. [CrossRef] [PubMed]

135. Zhai, S.; Hu, X.; Hu, Y.; Wu, B.; Xing, D. Visible light-induced crosslinking and physiological stabilization of diselenide-rich nanoparticles for redox-responsive drug release and combination chemotherapy. Biomaterials 2017, 121, 41-54. [CrossRef] [PubMed]

136. Yan, Q.; Chen, X.; Gong, H.; Qiu, P.; Xiao, X.; Dang, S.; Hong, A.; Ma, Y. Delivery of a TNF- $\alpha-$ derived peptide by nanoparticles enhances its antitumor activity by inducing cell-cycle arrest and caspase-dependent apoptosis. FASEB J. 2018. [CrossRef] [PubMed] 
137. Luesakul, U.; Puthong, S.; Neamati, N.; Muangsin, N. pH-responsive selenium nanoparticles stabilized by folate-chitosan delivering doxorubicin for overcoming drug-resistant cancer cells. Carbohydr. Polym. 2018, 181, 841-850. [CrossRef] [PubMed]

138. Jalalian, S.H.; Ramezani, M.; Abnous, K.; Taghdisi, S.M. Targeted co-delivery of epirubicin and NAS-24 aptamer to cancer cells using selenium nanoparticles for enhancing tumor response in vitro and in vivo. Cancer Lett. 2018, 416, 87-93. [CrossRef] [PubMed]

139. Nonsuwan, P.; Puthong, S.; Palaga, T.; Muangsin, N. Novel organic/inorganic hybrid flower-like structure of selenium nanoparticles stabilized by pullulan derivatives. Carbohydr. Polym. 2018, 184, 9-19. [CrossRef]

140. Xia, Y.; Guo, M.; Xu, T.; Li, Y.; Wang, C.; Lin, Z.; Zhao, M.; Zhu, B. siRNA-loaded selenium nanoparticle modified with hyaluronic acid for enhanced hepatocellular carcinoma therapy. Int. J. Nanomed. 2018, 13, 1539-1552. [CrossRef]

141. Abd-Rabou, A.A.; Shalby, A.B.; Ahmed, H.H. Selenium nanoparticles induce the chemo-sensitivity of fluorouracil nanoparticles in breast and colon cancer cells. Biol. Trace Elem. Res. 2018. [CrossRef]

142. Zhang, S.; Zhao, L.; Qiu, N.; Liu, Y.; Xu, B.; Zhu, H. On the hypoxic tumor targeting ability of two chitosan micelles loaded with oil-soluble CdSe quantum dots. Pharm. Dev. Technol. 2018, 23, 87-95. [CrossRef] [PubMed]

143. Pi, J.; Jiang, J.; Cai, H.; Yang, F.; Jin, H.; Yang, P.; Cai, J.; Chen, Z.W. GE11 peptide conjugated selenium nanoparticles for EGFR targeted oridonin delivery to achieve enhanced anticancer efficacy by inhibiting EGFR-mediated PI3K/AKT and Ras/Raf/MEK/ERK pathways. Drug Deliv. 2017, 24, 1549-1564. [CrossRef]

144. Chen, Q.; Xu, M.; Zheng, W.; Xu, T.; Deng, H.; Liu, J. Se/Ru-decorated porous metal-organic framework nanoparticles for the delivery of pooled siRNAs to reversing multidrug resistance in taxol-resistant breast cancer cells. ACS Appl. Mater. Interfaces 2017, 9, 6712-6724. [CrossRef] [PubMed]

145. Cadkova, M.; Kovarova, A.; Dvorakova, V.; Metelka, R.; Bilkova, Z.; Korecka, L. Electrochemical quantum dots-based magneto-immunoassay for detection of HE4 protein on metal film-modified screen-printed carbon electrodes. Talanta 2018, 182, 111-115. [CrossRef]

146. Liu, M.L.; Zou, H.Y.; Li, C.M.; Li, R.S.; Huang, C.Z. Aptamer-modified selenium nanoparticles for dark-field microscopy imaging of nucleolin. Chem. Commun. 2017, 53, 13047-13050. [CrossRef]

147. Moulick, A.; Milosavljevic, V.; Vlachova, J.; Podgajny, R.; Hynek, D.; Kopel, P.; Adam, V. Using CdTe/ZnSe core/shell quantum dots to detect DNA and damage to DNA. Int. J. Nanomed. 2017, 12, 1277-1291. [CrossRef] [PubMed]

148. Madhankumar, A.B.; Mrowczynski, O.D.; Patel, S.R.; Weston, C.L.; Zacharia, B.E.; Glantz, M.J.; Siedlecki, C.A.; Xu, L.C.; Connor, J.R. Interleukin-13 conjugated quantum dots for identification of glioma initiating cells and their extracellular vesicles. Acta Biomater. 2017, 58, 205-213. [CrossRef] [PubMed]

149. Zhao, Y.; Sun, Q.; Zhang, X.; Baeyens, J.; Su, H. Self-assembled selenium nanoparticles and their application in the rapid diagnostic detection of small cell lung cancer biomarkers. Soft Matter 2018, 14, 481-489. [CrossRef]

150. Zhu, C.N.; Chen, G.; Tian, Z.Q.; Wang, W.; Zhong, W.Q.; Li, Z.; Zhang, Z.L.; Pang, D.W. Near-infrared fluorescent $\mathrm{Ag}_{2} \mathrm{Se}$-cetuximab nanoprobes for targeted imaging and therapy of cancer. Small 2017, 13. [CrossRef]

151. Purohit, M.P.; Verma, N.K.; Kar, A.K.; Singh, A.; Ghosh, D.; Patnaik, S. Inhibition of thioredoxin reductase by targeted selenopolymeric nanocarriers synergizes the therapeutic efficacy of doxorubicin in MCF7 human breast cancer cells. ACS Appl. Mater. Interfaces 2017, 9, 36493-36512. [CrossRef]

152. Zhao, S.; Yu, Q.; Pan, J.; Zhou, Y.; Cao, C.; Ouyang, J.M.; Liu, J. Redox-responsive mesoporous selenium delivery of doxorubicin targets MCF-7 cells and synergistically enhances its anti-tumor activity. Acta Biomater. 2017, 54, 294-306. [CrossRef] [PubMed]

153. Pan, J.; Zhu, X.; Chen, X.; Zhao, Y.; Liu, J. Gd ${ }^{3+}$-Doped MoSe 2 nanosheets used as a theranostic agent for bimodal imaging and highly efficient photothermal cancer therapy. Biomater. Sci. 2018, 6, 372-387. [CrossRef] [PubMed]

154. Bidkar, A.P.; Sanpui, P.; Ghosh, S.S. Efficient induction of apoptosis in cancer cells by paclitaxel-loaded selenium nanoparticles. Nanomedicine 2017, 12, 2641-2651. [CrossRef] [PubMed]

155. Hauksdóttir, H.L.; Webster, T.J. Selenium and iron oxide nanocomposites for magnetically-targeted anti-cancer applications. J. Biomed. Nanotechnol. 2018, 14, 510-525. [CrossRef] [PubMed] 
156. Kolmas, J.; Pajor, K.; Pajchel, L.; Przekora, A.; Ginalska, G.; Oledzka, E.; Sobczak, M. Fabrication and physicochemical characterization of porous composite microgranules with selenium oxyanions and risedronate sodium for potential applications in bone tumors. Int. J. Nanomed. 2017, 12, 5633-5642. [CrossRef] [PubMed]

157. Fang, X.; Li, C.; Zheng, L.; Yang, F.; Chen, T. Dual-targeted selenium nanoparticles for synergistic photothermal therapy and chemotherapy of tumors. Chem. Asian J. 2018, 13, 996-1004. [CrossRef]

158. Chen, F.; Zhang, X.H.; Hu, X.D.; Liu, P.D.; Zhang, H.Q. The effects of combined selenium nanoparticles and radiation therapy on breast cancer cells in vitro. Artif. Cells Nanomed. Biotechnol. 2018, 46, 937-948. [CrossRef]

159. Maiyo, F.; Singh, M. Selenium nanoparticles: Potential in cancer gene and drug delivery. Nanomedicine 2017, 12, 1075-1089. [CrossRef]

160. Zhai, X.; Zhang, C.; Zhao, G.; Stoll, S.; Ren, F.; Leng, X. Antioxidant capacities of the selenium nanoparticles stabilized by chitosan. J. Nanobiotechnol. 2017, 15, 1-12. [CrossRef]

161. Kumari, M.; Ray, L.; Purohit, M.P.; Patnaik, S.; Pant, A.B.; Shukla, Y.; Kumar, P.; Gupta, K.C. Curcumin loading potentiates the chemotherapeutic efficacy of selenium nanoparticles in HCT116 cells and Ehrlich's ascites carcinoma bearing mice. Eur. J. Pharm. Biopharm. 2017, 117, 346-362. [CrossRef]

162. Wadhwani, S.A.; Shedbalkar, U.U.; Singh, R.; Chopade, B.A. Biogenic selenium nanoparticles: Current status and future prospects. Appl. Microbiol. Biotechnol. 2016, 100, 2555-2566. [CrossRef] [PubMed]

163. Vetchinkina, E.; Loshchinina, E.; Kursky, V.; Nikitina, V. Reduction of organic and inorganic selenium compounds by the edible medicinal basidiomycete Lentinula edodes and the accumulation of elemental selenium nanoparticles in its mycelium. J. Microbiol. 2013, 51, 829-835. [CrossRef] [PubMed]

164. Tugarova, A.V.; Kamnev, A.A. Proteins in microbial synthesis of selenium nanoparticles. Talanta 2017, 174, 539-547. [CrossRef] [PubMed]

165. Prasad, K.S.; Patel, H.; Patel, T.; Patel, K.; Selvaraj, K. Biosynthesis of Se nanoparticles and its effect on UV-induced DNA damage. Colloids Surf. B Biointerfaces 2013, 103, 261-266. [CrossRef] [PubMed]

166. Zonaro, E.; Piacenza, E.; Presentato, A.; Monti, F.; Dell'Anna, R.; Lampis, S.; Vallini, G. Ochrobactrum sp. MPV1 from a dump of roasted pyrites can be exploited as bacterial catalyst for the biogenesis of selenium and tellurium nanoparticles. Microb. Cell Fact. 2017, 16, 215. [CrossRef] [PubMed]

167. Ramya, S.; Shanmugasundaram, T.; Balagurunathan, R. Biomedical potential of actinobacterially synthesized selenium nanoparticles with special reference to anti-biofilm, anti-oxidant, wound healing, cytotoxic and anti-viral activities. J. Trace Elem. Med. Biol. 2015, 32, 30-39. [CrossRef] [PubMed]

168. Saratale, R.G.; Karuppusamy, I.; Saratale, G.D.; Pugazhendhi, A.; Kumar, G.; Park, Y.; Ghodake, G.S.; Bharagava, R.N.; Banu, J.R.; Shin, H.S. A comprehensive review on green nanomaterials using biological systems: Recent perception and their future applications. Colloids Surf. B Biointerfaces 2018, 170, 20-35. [CrossRef]

169. Eswayah, A.S.; Smith, T.J.; Scheinost, A.C.; Hondow, N.; Gardiner, P.H.E. Microbial transformations of selenite by methane-oxidizing bacteria. Appl. Microbiol. Biotechnol. 2017, 101, 6713-6724. [CrossRef]

170. Song, D.; Li, X.; Cheng, Y.; Xiao, X.; Lu, Z.; Wang, Y.; Wang, F. Aerobic biogenesis of selenium nanoparticles by Enterobacter cloacae Z0206 as a consequence of fumarate reductase mediated selenite reduction. Sci. Rep. 2017, 7, 3239. [CrossRef]

171. Fernandez-Llamosas, H.; Castro, L.; Blazquez, M.L.; Diaz, E.; Carmona, M. Speeding up bioproduction of selenium nanoparticles by using Vibrio natriegens as microbial factory. Sci. Rep. 2017, 7, 16046. [CrossRef]

172. Quintana, M.; Haro-Poniatowski, E.; Morales, J.; Batina, N. Synthesis of selenium nanoparticles by pulsed laser ablation. Appl. Surf. Sci. 2002, 195, 175-186. [CrossRef]

173. Chang, S.Q.; Dai, Y.D.; Kang, B.; Han, W.; Chen, D. Gamma-radiation synthesis of silk fibroin coated CdSe quantum dots and their biocompatibility and photostability in living cells. J. Nanosci. Nanotechnol. 2009, 9, 5693-5700. [CrossRef] [PubMed]

174. Guisbiers, G.; Lara, H.H.; Mendoza-Cruz, R.; Naranjo, G.; Vincent, B.A.; Peralta, X.G.; Nash, K.L. Inhibition of Candida albicans biofilm by pure selenium nanoparticles synthesized by pulsed laser ablation in liquids. Nanomedicine 2017, 13, 1095-1103. [CrossRef] [PubMed]

175. Kasinski, A.L.; Slack, F.J. Epigenetics and genetics. MicroRNAs en route to the clinic: Progress in validating and targeting microRNAs for cancer therapy. Nat. Rev. Cancer 2011, 11, 849-864. [CrossRef] [PubMed] 
176. Berndsen, R.H.; Abdul, U.K.; Weiss, A.; Zoetemelk, M.; Te Winkel, M.T.; Dyson, P.J.; Griffioen, A.W.; Nowak-Sliwinska, P. Epigenetic approach for angiostatic therapy: Promising combinations for cancer treatment. Angiogenesis 2017, 20, 245-267. [CrossRef] [PubMed]

177. Speckmann, B.; Grune, T. Epigenetic effects of selenium and their implications for health. Epigenetics 2015, 10, 179-190. [CrossRef] [PubMed]

178. Jablonska, E.; Reszka, E. Selenium and epigenetics in cancer: Focus on DNA methylation. Adv. Cancer Res. 2017, 136, 193-234.

179. Xiang, N.; Zhao, R.; Song, G.; Zhong, W. Selenite reactivates silenced genes by modifying DNA methylation and histones in prostate cancer cells. Carcinogenesis 2008, 29, 2175-2181. [CrossRef]

180. de Miranda, J.X.; Andrade Fde, O.; Conti, A.; Dagli, M.L.; Moreno, F.S.; Ong, T.P. Effects of selenium compounds on proliferation and epigenetic marks of breast cancer cells. J. Trace Elem. Med. Biol. 2014, 28, 486-491. [CrossRef]

181. Hu, C.; Liu, M.; Zhang, W.; Xu, Q.; Ma, K.; Chen, L.; Wang, Z.; He, S.; Zhu, H.; Xu, N. Upregulation of KLF4 by methylseleninic acid in human esophageal squamous cell carcinoma cells: Modification of histone $\mathrm{H} 3$ acetylation through HAT/HDAC interplay. Mol. Carcinog. 2015, 54, 1051-1059. [CrossRef]

182. Wu, J.C.; Wang, F.Z.; Tsai, M.L.; Lo, C.Y.; Badmaev, V.; Ho, C.T.; Wang, Y.J.; Pan, M.H. Se-Allylselenocysteine induces autophagy by modulating the $\mathrm{AMPK} / \mathrm{mTOR}$ signaling pathway and epigenetic regulation of PCDH17 in human colorectal adenocarcinoma cells. Mol. Nutr. Food Res. 2015, 59, 2511-2522. [CrossRef] [PubMed]

183. Silvers, A.L.; Lin, L.; Bass, A.J.; Chen, G.; Wang, Z.; Thomas, D.G.; Lin, J.; Giordano, T.J.; Orringer, M.B.; Beer, D.G.; et al. Decreased selenium-binding protein 1 in esophageal adenocarcinoma results from posttranscriptional and epigenetic regulation and affects chemosensitivity. Clin. Cancer Res. 2010, 16, 2009-2021. [CrossRef] [PubMed]

184. Khalkar, P.; Ali, H.A.; Codo, P.; Argelich, N.D.; Martikainen, A.; Arzenani, M.K.; Lehmann, S.; Walfridsson, J.; Ungerstedt, J.; Fernandes, A.P. Selenite and methylseleninic acid epigenetically affects distinct gene sets in myeloid leukemia: A genome wide epigenetic analysis. Free Radic. Biol. Med. 2018, 117, 247-257. [CrossRef] [PubMed]

185. Hosnedlova, B.; Kepinska, M.; Skalickova, S.; Fernandez, C.; Ruttkay-Nedecky, B.; Peng, Q.; Baron, M.; Melcova, M.; Opatrilova, R.; Zidkova, J.; et al. Nano-selenium and its nanomedicine applications: A critical review. Int. J. Nanomed. 2018, 13, 2107-2128. [CrossRef] [PubMed]

186. Sakr, T.M.; Korany, M.; Katti, K.V. Selenium nanomaterials in biomedicine-An overview of new opportunities in nanomedicine of selenium. J. Drug Deliv. Sci. Tec. 2018, 46, 223-233. [CrossRef] 